\title{
Evaluation of neuroprotective effects of Canna indica $L$ against aluminium chloride induced memory impairment in rats
}

\author{
Prachi S. Ojha ${ }^{1} \cdot$ Prakash R. Biradar $^{1} \mathbb{D} \cdot$ Siddarth Tubachi ${ }^{1} \cdot$ Vishal S. Patil $^{2}$
}

Received: 7 August 2021 / Accepted: 24 December 2021

(c) The Author(s), under exclusive licence to Institute of Korean Medicine, Kyung Hee University 2022

\begin{abstract}
Memory disorders are the progressive neurological disorder, mainly causing dementia, memory loss and cognitive dysfunctions. The current study is aimed to experimentally validate the crude extract of Canna indica aerial parts (CIA) and root (CIR) against aluminium chloride induced altered memory in rats. Initially, methanolic extract of CIA, hydroalcoholic extract of CIR, and their combination of CIA + CIR were screened for Invitro antioxidant activity via 2,2-diphenyl-1-picrylhydrazyl (DPPH) and nitric oxide (NO) assays, acetylcholinesterase (AChE) inhibitory assay and were also screened for their memory enhancing activity by in-vivo models such as elevated plus maze (EPM), morris water maze (MWM), cooks pole climb (CPC), Actophotometer, novel object recognition (NOR), and T-maze. Aluminium chloride $\left(\mathrm{AlCl}_{3}\right)(17 \mathrm{mg} / \mathrm{kg} / \mathrm{day}$ p.o.) for 21 days, was used as an Alzheimer's disease inducing agent and Donepezil (AChE inhibitor) as a standard treatment agent. The AChE, butyrylcholinesterase (BChE) activity and malondialdehyde (MDA) level were significantly increased, and glutathione (GSH), total protein (TP), catalase (CAT), and Dopamine were decreased only in $\mathrm{AlCl}_{3}$ treated rats and treatment with CIA $200 \mathrm{mg} / \mathrm{kg}$ and CIA + CIR $200 \mathrm{mg} / \mathrm{kg}$ significantly reversed these mechanisms. Histopathology of cortex and hippocampus was examined at $40 \times$ magnification, indicating maintain of integrity and architecture of CA1 and CA 3 neuronal cells compared to control and standard groups. The in vivo studies of interospective and exteroceptive behavior models (EPM), MWM, CPC, Actophotometer, NOR, T-maze revealed that $\mathrm{AlCl}_{3}$ administration enhanced transfer latency (TL), escape latency time (ELT) and decreases locomotion, discriminatory index, and percentage alternation respectively. However, treatment with CIA and CIA + CIR $200 \mathrm{mg} / \mathrm{kg}$ highly significantly reversed the pathological changes of disease, extracts of Canna indica of both root and aerial parts phyto constituents are rich in flavonoids, phlobatannins, anthocyanin pigments, saponins, alkaloids, steroids, terpenoids etc. Which will decipher the acetylcholinestrase inhibitory, antioxidant and antiinflammatory activity, will ameliorate the pathological state of Alzheimer disease.
\end{abstract}

Prakash R. Biradar

prakashbiradar@klepharm.edu; prakashrb123@gmail.com

1 Department of Pharmacology and Toxicology, KLE College of Pharmacy, KLE Academy of Higher Education and Research, Belagavi, Karnataka 590010, India

2 ICMR- National Institute of Traditional Medicine, Belagavi, Karnataka 590010, India 


\section{Graphical abstract}

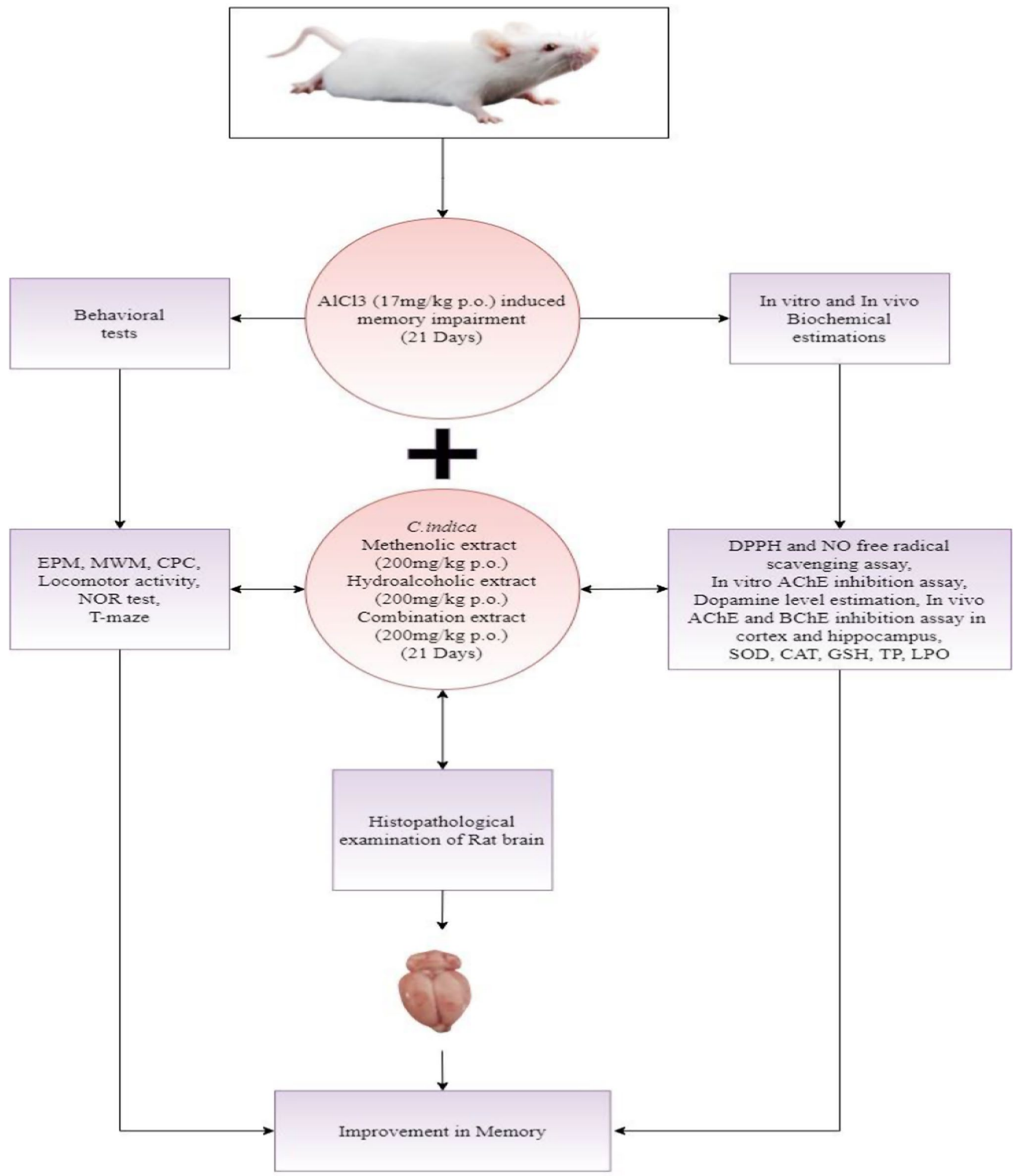

Keywords Aluminium chloride $\cdot$ Memory disorder $\cdot$ Canna indica $\mathrm{L} \cdot$ Acetylcholinestrase $\cdot$ Dopamine $\cdot$ Donepzil 


$\begin{array}{ll}\text { Abbreviations } & \\ \mathrm{AD} & \text { Alzhemeir disease } \\ \mathrm{AlCl}_{\mathbf{3}} & \text { Aluminum chloride } \\ \mathrm{AChE} & \text { Acetylcholinestrase enzyme } \\ \mathrm{BChE} & \text { Butrylcholinestrase enzyme } \\ \mathrm{ELT} & \text { Escape latency time } \\ \mathrm{CIA}+\text { CIR200 } & \text { Canna indica } \text { aerial + root part }(200 \mathrm{mg} / \\ & \text { kg) Group } \\ \mathrm{CIA} 200 & \text { Canna indica } \text { aerial part }(200 \mathrm{mg} / \mathrm{kg}) \\ & \text { Group } \\ \text { CIR200 } & \text { Canna indica } \text { root part }(200 \mathrm{mg} / \mathrm{kg}) \\ & \text { Group } \\ \mathrm{CPC} & \text { Cook's pole climbing } \\ \mathrm{CAT} & \text { Catalase } \\ \mathrm{EPM} & \text { Elevated plus maze } \\ \mathrm{DPZ} & \text { Donepezil } \\ \mathrm{GSH} & \text { Glutathione } \\ \mathrm{IC} & \text { Inhibition concentration } \\ \mathrm{LPO} & \text { Lipid peroxidation } \\ \mathrm{MDA} & \text { Malondialdehyde } \\ \text { LPO } & \text { Lipid peroxidation } \\ \text { MWM } & \text { Morris water maze } \\ \text { NOR } & \text { Novel object recognition } \\ \text { N } & \text { Number of groups } \\ \text { NC } & \text { Negative control } \\ \text { PC } & \text { Positive control } \\ \text { p.o. } & \text { Per. oral } \\ \text { TL } & \text { Transfer latency } \\ \text { SOD } & \text { Super oxide dismutase } \\ \text { STL } & \text { Step through latency } \\ \text { TP } & \text { Total protein } \\ \text { ROS } & \text { Reactive oxygen species } \\ & \end{array}$

\section{Introduction}

Alzheimer disease (AD) is a devastative neurodegenerative syndrome (progressive memory decline) reflecting the dysfunction of cerebral nerve cells and abnormal neurotransmitter activities. Currently more than 55 million people live with dementia worldwide, and there are nearly 10 million new cases every year (WHO report 2021). India is going through a demographic shift, with the elderly population significantly increasing. In India, life expectancy has nearly doubled, from 36.98 years in 1950-1960 to 69.27 years in 2015-2020. In the twenty first century, understanding the complete etiology, pathogenesis, and ascertaining disease modifying agents/therapy against $\mathrm{AD}$ is one of the most important challenges. AD is biochemically characterized by the $A \beta$ elevation, insoluble protein aggregates (neuritic senile plaques and neurofibrillary tangles) accumulation, central cholinergic and dopaminergic systems impairment, increased cerebral oxidative stress etc., while it is clinically characterized by performance abnormality, behavior worsening, thought leisureliness etc. AD is associated with a heterogeneous cause due to the multiple gene mutations and accounted for complex multi- proteins and multi-pathways mechanisms. (Blennow et al. 2006; Korczyn and Vakhapova, 2007; Bachurin et al. 2017). The inducing compound Aluminium chloride causes the highly reactive oxygen species (ROS) leading the Neuroinflammation, $A \beta$ and Tau protein degradation characterizing similar to AD pathogenesis (Prema et al. 2017).

To date, AD symptoms can be managed with two classes of drugs that are approved by the US-FDA, which includes (I) Cholinesterase (ChE) inhibitors (II) NMD Aantagonists (Colović et al., 2013). However, these agents provide a partial improvement of memory and cognitive function and are associated with several side effects viz. bronchospasm, bradycardia, increased respiratory secretion, hypotension, decreased intraocular pressure, nausea and vomiting during long term therapy. Also, these agents lose effectiveness as the disease progresses (Ali et al. 2015).

Traditional medicinal plants have received valuable attention in the management of various ailments, India is considered as a Goldmine for medicinal plants and their traditional uses with less side effects and multiple target mechanism for the neurodegenerative diseases. WHO has recommended and encouraged the use of traditional herbs remedies during the COVID-19 pandemic, because of their therapeutic efficacy, safety and availability (Gautam et al. 2020).

Canna indica, a member of the "Cannaceae" family and "Canna" genus. Traditionally, rhizomes are used for gonorrhoea, dropsy, febrifuge, dyspepsia, and as an antipyretic through decoction, and roots were utilized against amenorrhoea (Kanase and Vishwakarma 2018). The leaves were utilized for malaria, rheumatic pain, and arthritis and possess Haemostatic effect (Lin et al 2011). The flowers were used for eye diseases and their decoction for external wound healing. Numerous pharmacological experiments demonstrated its therapeutics against inflammation, diabetes, viral diseases, immune related disorders, brain disorders including its effect on Acetylcholinesterase enzyme. (Chigurupati et al. 2021; Talluri et al. 2018) Canna indica whole plant extracts exhibited potential radical scavenging, anti-inflammatory and were reported to possess neuroprotective activity (Chigurupati et al. 2021). Canna indicia enriched with flavonoids, phlobatannins, anthocyanin pigments, tannins, saponins, cardiac glycosides, alkaloids, steroids, terpenoids, etc. bioactive molecules (Oladotun et al 2019).

However, there is a paucity of scientific reports on Canna indica $\mathrm{L}$., constituent's molecular mechanisms in the treatment of AD. Herein, we designed this study to explore the possible mechanisms of Canna indica aerial part and root extract in $\mathrm{AlCl}_{3}$ induced memory impairment by utilizing 
Invivo studies by interospective and exteroceptive behavior models as well Invitro biochemical estimations.

\section{Materials used in the current study}

\section{Chemicals}

Aluminium chloride $\left(\mathrm{AlCl}_{3}\right)$ (Sigma, USA), Donepezil (DPZ) (Cipla, Goa), Acetylthiocholine iodide (Sigma, USA), Butyrylthiocholine iodide (Sigma, USA). 2,2-diphenyl-1 picrylhydrazyl (DPPH) Dopamine, DTNB (Sigma, USA) and other analytical graded chemicals.

\section{Plant material}

The aerial parts and root of Canna indica L. gathered from Sujoy and Aditya Nursery, Chicalim, Goa, India and authenticated by the plant taxonomist from ICMR-NITM, Belagavi. Accession number: RMRC -1584. The collected plant specimen was stored as an herbarium for future reference. The fresh plant material was washed properly using running water and to remove dust particles and shade dried at room temperature. The dried plant material was further crushed into coarse powder using a grinder and exposed to the extraction method.

\section{Extraction}

1. The aerial part dried coarse powder $1 \mathrm{~kg}$ were subjected to the maceration technique using Solvent: methanol $(95 \%)$ as a solvent

2. The dried root parts coarse powder $1 \mathrm{~kg}$ was subjected to the maceration technique using Hydroalcohol (Water:Ethanol 3:7).

Both the mixtures were kept for 7 days with random shaking. After 7 days, the solvent is filtered out and concentrated under reduced pressure at $45-55^{\circ} \mathrm{C}$ using a rotary evaporator. The obtained extract was sticky, which were further air-dried, collected in an amber color glass container, and stored in the refrigerator.

The marc was used for Soxhlet extraction with the respective solvents i.e. aerial marc (methanol-75\%), Root part (ethanol-70\%). Phytoconstituents screening tests were carried out using standard protocols.

\section{Flavonoid and phenolic content}

Total flavonoid content of methanolic extract of aerial part and hydroalcoholic extract of root part of Canna indica was performed as explained by Zhishen et al. (1999) with equivalent to Rutin Similarly, Total phenolic content of both the extracts were performed as mentioned by Baba et al (2014) with equivalent to gallic acid and IC50 value is expressed

\section{In-vitro antioxidant activity}

The DPPH free radical scavenging assay of the methanolic extract of the aerial part and hydroalcoholic extract of root part of Canna indica was performed as explained by Tharun and Kumar (2013) and Noreen et al. (2017). Similarly, the nitrous oxide free radical scavenging assay for both the extracts was carried out as illustrated by Boora et al. (2014). Ascorbic acid was used as a standard. Appropriate controls were taken for standard and test compounds and IC50 value was calculated.

\section{In-vitro acetylcholinesterase activity}

Methanolic extract of the aerial part and hydroalcoholic extract of the root part of Canna indica was evaluated for acetylcholinesterase inhibitory activity by using Ellman's method (Dhanasekaran et al. 2015). The concentration range from 10 to $320 \mu \mathrm{g} / \mathrm{mL}$ for extract and 1 to $32 \mu \mathrm{g} / \mathrm{mL}$ for Donepezil was tested. $1.7 \mathrm{~mL}$ (pH 8.0) and $250 \mu \mathrm{L}$ different concentrations of extract and Donepezil was prepared. To the above mixture, $10 \mu \mathrm{L}$ of $6.67 \mathrm{U} \mathrm{mL}^{-1} \mathrm{AChE}$ enzyme and $20 \mu \mathrm{L}$ of DTNB was added. The mixture was incubated for $15 \mathrm{~min}$, after incubation added $10 \mu \mathrm{L}$ of Acetylthiocholine iodide, and the absorbance was read at $412 \mathrm{~nm}$ every $45 \mathrm{~s}$ for $3 \mathrm{~min}$. The percentage inhibition was calculated from the change in Abs w.r.t. change in time.

$\%$ Inhibition $=100-\frac{\text { SampleAbs }}{\text { BlankAbs }} \times 100$

IC50 was calculated between the inhibition percentage $\mathrm{v} / \mathrm{s}$ extraction concentration.

\section{Experimental animals}

To evaluate the memory enhancing capacity of the Canna indica, male Wistar rats having 250-300 g weight of 8 weeks old rats were used. All the animals were housed in a hygienic and translucent polypropylene cage. Further animals were randomized and made into six groups $(\mathrm{N}=6$ and $n=6) N=$ Number of groups and $n=$ Number of animals in each group. All the animals were kept under 12/12 $\mathrm{h}$ natural light-dark cycle $\left[27^{\circ} \mathrm{C}\right.$ temp. and $\left.45-55 \% \mathrm{RH}\right]$. The overall research procedure was revised and approved by the IAEC, KLE College of Pharmacy, Belagavi.Resolution NoKLECOP/CPCSEA- Reg.No.221/Po/Re/S/2000/CPCSEA, Res. No 29-03/09/2020. 


\section{Experimental study design}

Male Wistar rats were divided into 6 groups (Study Design) LD50 of Canna indica was reported to be $2000 \mathrm{mg} / \mathrm{kg}$ for 28 days with no mortality. Thus, an intermediate dose of $200 \mathrm{mg} / \mathrm{kg}$ was chosen from 1/10th of the LD50 for the experiment. Control group animals received normal food and water throughout the experiment. Negative Control (NC) group received $\mathrm{AlCl}_{3}(17 \mathrm{mg} / \mathrm{kg} /$ day p.o.) for 21 days. Positive Control (PC) group received $\mathrm{AlCl}_{3}(17 \mathrm{mg} / \mathrm{kg} /$ day p.o.) along with Donepezil (DPZ) ( $3 \mathrm{mg} / \mathrm{kg}$ p.o.) for 21 days. CIA200, CIR200, and CIA+CIR 200 group received $\mathrm{AlCl}_{3}$ (17 mg/kg/day p.o.) along with extracts for 21 days. Before initiating the study, acquisition trials were carried out for all the animals using Elevated plus maze (EPM), Morris water maze (MWM), Cooks pole climb (CPC), T-maze, novel object recognition (NOR), and Actophotometer. After subjecting to the test agent, changes in the Latency were examined on 0th (first dose) 7th, 14th and 21st day. After completion of the in-vivo studies, rats were euthanatized, brains were isolated and cerebral cortex, hippocampus $\mathrm{AChE}$ and BChE enzyme level and whole brain Dopamine, lipid peroxidation (LPO), reduced glutathione GSH, malondialdehyde (MDA), total protein (TP), superoxide dismutase (SOD) and catalase (CAT) level were measured.

Study Design In vivo study plan, $\mathrm{N}=6(\mathrm{~N}-\mathrm{No}$. of groups) and $\mathrm{n}=6$ ( $\mathrm{n}$-No. of animals in each groups)

\begin{tabular}{|c|c|}
\hline Groups (N) & Treatment (n) \\
\hline Control & Received normal food and water \\
\hline Negative Control (NC) & $\begin{array}{l}\text { Received } \mathrm{AlCl}_{3}(17 \mathrm{mg} / \mathrm{kg} \\
\text { p.o. })-21 \text { days }\end{array}$ \\
\hline Positive Control (PC) & $\begin{array}{c}\mathrm{AlCl}_{3}(17 \mathrm{mg} / \mathrm{kg} \text { p.o. })+\text { Donepezil } \\
\mathrm{HCl} .(3 \mathrm{mg} / \mathrm{kg} \text { p.o. })-21 \text { days }\end{array}$ \\
\hline $\begin{array}{l}\text { Canna indica Aerial Mentah- } \\
\text { nolic extract (CIA) } 200\end{array}$ & $\begin{array}{l}\mathrm{AlCl}_{3}(17 \mathrm{mg} / \mathrm{kg} \text { p.o. })+\mathrm{CIA} \\
\quad \text { extract }(200 \mathrm{mg} / \mathrm{kg} \text { p.o. })- \\
21 \text { days }\end{array}$ \\
\hline $\begin{array}{l}\text { Canna indica Root hydroalcholic } \\
\text { extract (CIR) } 200\end{array}$ & $\begin{array}{l}\mathrm{AlCl}_{3}(17 \mathrm{mg} / \mathrm{kg} \text { p.o. })+\mathrm{CIR} \\
\text { extract }(200 \mathrm{mg} / \mathrm{kg} \text { p.o. })- \\
21 \text { days }\end{array}$ \\
\hline Canna indica CIA + CIR 200 & $\begin{array}{l}\mathrm{AlCl}_{3}(17 \mathrm{mg} / \mathrm{kg} \\
\text { p.o. })+\mathrm{CIA}+\mathrm{CIR} \text { extract } \\
(200 \mathrm{mg} / \mathrm{kg} \text { p.o. })-21 \text { days }\end{array}$ \\
\hline
\end{tabular}

\section{In-vivo screening model for memory: Morris water maze (MWM) test}

MWM is a big round water tank "diameter: $110 \mathrm{~cm}$ and height: $60 \mathrm{~cm}$ " consisting of a white surface and that is filled using opaque water (Temp. $26 \pm 2{ }^{\circ} \mathrm{C}$ ) to a distance (depth) of $30 \mathrm{~cm}$. The MWM tank circle is divided into 4 equal quadrants [North Quadrant 1, East Quadrant 2, West Quadrant 3, and South Quadrant 4]. Further, it consists of a $10 \mathrm{~cm}$ diameter platform in a constant position. The ELT of the individual rat was noted at the $60 \mathrm{~s}$ cut-off time (Ishola et al. 2018; Biradar et al. 2020).

Index of memory improvement- Escape Latency Time (ELT).

\section{Elevated plus maze (EPM) test}

EPM contains of 2 closed and 2 open arms (four arms; equal dimensions of $50 \times 10 \mathrm{~cm}$ ). These 4 arms connect at central with a $10 \times 10 \mathrm{~cm}$ square gap as an initial point. The transfer latency (TL) was recorded via stopwatch by keeping rats independently toward one side of the open arm. The EPM TL cut-off was set to $60 \mathrm{~s}$ throughout the study. In EPM, when the rat does not enter the closed arm, such rat was directed back into one of the closed arms, and $60 \mathrm{~s}$ TL was given. (Bhuvanendran et al. 2018 and Biradar et al. 2020).

Index of memory improvement -A drop of transfer Latency(TL) by test drug.

\section{Locomotor activity by actophotometer test}

The individual rat locomotion was assessed via actophotometer at a cut-off time of $5 \mathrm{~min}$. The system consists of a photocell connected to the circuit with a counter. The beam of light passing on the photocell is cut off by the moving animal, then a count is recorded. On the 0th, 7th, 14th, and 21st day, individual group readings were noted. Before initiating the experiment, $10 \%$ ethanol was used to wipe the chamber for avoiding the animal odour. (Goverdhan et al. 2012).

Index of memory improvement -Increase in locomator activity neuromuscular coordination and spatial learning by test drug.

\section{Cook's pole climbing (CPC) test}

The escape latency/conditional avoidance of each rat during learning and its retention was screened by CPC. The ground part consists in grid rods that acted as a shock stimulus. First, individual rats were trained and readings were noted acquisition, the retention trail was noted 0th, 7th, 14th, and 21 st day. The cut-off time of $120 \mathrm{~s}$ was considered for evaluation (Goverdhan et al. 2012).

Index of memory improvement - Exterceptive punishment based valence memory and strength of the neuromuscular activity of the treated drug.

\section{Novel object recognition (NOR) test}

This test is utilized to assess short- and long-term memory. The test includes both acquisition and retention trials. 
During the acquisition trial two identical objects (green balls) were placed equidistant from each other. Further, for $60 \mathrm{~s}$ animals were placed in the arm and then placed back in the cage. The process was repeated for all the animals for 7 days (training period). During this trial after a period of $30 \mathrm{~min}$, to avoid the bias for a particular location of identical and novel objects, interchanged the objects from left to right. After training, the same methodology was performed for the retention trial after a period of $30 \mathrm{~min}$. Here, one green ball (identical object) is replaced with the red ball (novel object), and the time is taken to explore an object was noted (Antunes et al 2012)

Object exploration recording includes:

- Animal head to orient towards the object within a distance of $2 \mathrm{~cm}$.

- Animal to sniffing, touching, and licking the object with the paws.

Discrimination index (DI in \%) was calculated by using $\mathrm{DI}(\%)=(\mathrm{A} 1-\mathrm{A} 2) /(\mathrm{A} 1+\mathrm{A} 2)$ and $\mathrm{DI}(\%)$. $=(\mathrm{A} 1-\mathrm{B}) /(\mathrm{A} 1+\mathrm{B})$ formula.

1. Time spent with familiar object 1 (A1)

2. Time spent with the familiar object 2 (A2)

3. Time spent with the novel object (B)

Index of memory improvement: assessment of working memory of the treated drug.

\section{T-maze test}

The test involves both acquisition and retention sessions. Initially, animals were trained for 7 consecutive days. After that, on the 0th day (Treatment period) food was placed in one side arm (left arm we selected) before beginning the experiment. The overnight fasted animal is placed in the start box for $60 \mathrm{~s}$. Then, a slow sliding door was opened noted the number of entries in the left arm (right choices). Similarly, the tests were repeated on day 12th and 21 st day.

$\%$ Alternation was calculated by dividing the number of entries into the left arm in the acquisition and during the treatment period (Wenk et al. 1998).

Index of memory improvement: Assessment of reward based memory of the treated drug.

\section{Biochemical estimation}

\section{$\mathrm{AChE}$ and $\mathrm{BChE}$ level in the cerebral cortex and hippocampus}

At the end of the study, the rats were decapitated, their brains removed quickly and kept in ice cold saline. Cortex and hippocampus were isolated and placed in an icecold water container to stop the enzymatic reactions. Ellman's method 1961 was followed to estimate AChE and $\mathrm{BChE}$ level in the cortex and hippocampus regions of the brain. For this, approximately $100 \mathrm{mg}$ of the isolated sections was weighed and homogenated in Phosphate buffer [0.1 M; pH 8.0]. To $0.4 \mathrm{~mL}$ above mixture (homogenate) was added, (1) $2.6 \mathrm{~mL} 0.1 \mathrm{M}(\mathrm{pH}$ 8) Phosphate buffer (2) $100 \mu \mathrm{L}$ of $10 \mathrm{mM} 5,5$-dithio-bis-(2-nitrobenzoic acid (DTNB) and mixed well. Further, $20 \mu \mathrm{L}$ of Acetylthiocholine iodide $(\mathrm{AChI})(0.075 \mathrm{M})$ was added to the above mixture. The Abs was then noted at $412 \mathrm{~nm}$ for $5 \mathrm{~min}$ "The rate of moles of substrate hydrolyzed/ $/ \mathrm{min} / \mathrm{g}$ of tissue is calculated by"

$\mathrm{R}=5.74 \times 10^{-4}(\Delta \mathrm{A} / \mathrm{Co})$

where R Rate, in moles of substrate hydrolyzed per min per gram of tissue. $\Delta \mathrm{A}$ change in Abs per min, Co Conc. of tissue $(\mathrm{mg} / \mathrm{mL})$.

\section{Determination of MDA level in LPO}

To the $0.2 \mathrm{~mL}$ of tissue homogenate was taken. $0.2 \mathrm{~mL}$ of SLS $(8.1 \% \mathrm{w} / \mathrm{v})$ was added followed by $1.5 \mathrm{~mL}$ of $20 \%$ $\mathrm{CH} 3 \mathrm{COOH}$ and $1.5 \mathrm{~mL}$ TBA $(0.8 \%)$. The above mixture was vortexed for $1 \mathrm{~min}$ and diluted up to $4 \mathrm{~mL}$ using DM water. Further, it was boiled at $90^{\circ} \mathrm{C}$ for $1 \mathrm{~h}$ using the water bath. The whole mixture was cooled and $1 \mathrm{~mL}$ of $\mathrm{DM}$ water was added followed by $5 \mathrm{~mL}$ mixture of "pyridine:nbutanol" $(1: 15 \mathrm{v} / \mathrm{v})$. Lastly, the mixture was centrifuged at $4000 \mathrm{rpm}$ for $10 \mathrm{~min}$. The Abs of the organic layer was read at $532 \mathrm{~nm}$. (Ohkawa et al. 1979; Ramakrishnan et al. 2015).

Cerebrum malondialdehyde (MDA) $\mathrm{mg}^{-1}$ of LPO level was estimated and expressed in nanomoles using the formula,

$\mathrm{MDA}=\mathrm{nmoles}$ of $\mathrm{MDA} / \mathrm{mg}$ of $\mathrm{LPO}(\mathrm{P})$ in the cerebrum is

$\mathrm{C}=\mathrm{A} \times(\mathrm{V} / \mathrm{E}) \times \mathrm{P}$

where $\mathrm{A}=\mathrm{Abs}$ at $535 \mathrm{~nm}, \mathrm{~V}=$ Volume of mixture, $\mathrm{E}=$ Extinction coefficient. 


\section{Determination of reduced $\mathrm{\gamma}$-L-Glutamyl-L-cysteinyl- glycine (GSH)}

Ellman GL 1959 method was utilized to estimate wholebrain reduced GSH level. To $0.25 \mathrm{~mL}$ of tissue homogenate, $2.5 \mathrm{~mL}$ sodium phosphate buffer was added followed by $50 \mu \mathrm{L}(5,5$-dithio-bis-(2-nitrobenzoic acid) DTNB [pH 7.0]. The mixture was then vortexed the above mixture and incubated at $25-27^{\circ} \mathrm{C}$ for $2 \mathrm{~min}$. Within $15 \mathrm{~min}$, at $412 \mathrm{~nm}$, Abs of the mixture was read and expressed $\gamma$-L-GlutamylL-cysteinyl-glycine (GSH) level in $\mu$ moles/mg of tissue.

$\mathrm{Co}=\mathrm{A} \times \mathrm{DN}$

where $\mathrm{Co}$ is the original concentration $\mathrm{A}$ is $\mathrm{Ab}$ at $412 \mathrm{~nm}$, $\mathrm{N}$ is molar extinction coefficient i.e. $13,600 / \mathrm{M} / \mathrm{cm}$. Dilution factor (D).

\section{Determination of SOD}

The capacity of SOD to antagonize the auto-oxidation of epinephrine to adrenochrome in the presence of alkaline ph. To the $25 \mu \mathrm{L}$ of homogenate sample, added $0.1 \mathrm{mM}$ of epinephrine in carbonate buffer (pH 10.2). At $295 \mathrm{~nm}$, the adrenochrome formation in the above mixture was measured using the ELISA platereader. Further, the SOD level was determined from the total protein value and expressed in $\mathrm{U} /$ mg of protein (Misra et al. 1972).

\section{Determination of total protein}

Taken, $2.25 \mathrm{~mL}$ of $0.5 \mathrm{MNaOH}$ was added to $0.25 \mathrm{~mL}$ of tissue homogenate. Then, $0.5 \mathrm{~mL}$ was pipetted out from the above mixture and $0.5 \mathrm{~mL}$ of $10 \%$ TCA was added followed by centrifugation at $3000 \mathrm{rpm}$ for $10 \mathrm{~min}$ at $4{ }^{\circ} \mathrm{C}$. After, this the supernatant was discarded and the remaining precipitate was dissolved in $0.5 \mathrm{~mL}$ of $0.5 \mathrm{M} \mathrm{NaOH}$ and $2 \mathrm{~mL}$ of Alkaline mixture. Further, after waiting for $10 \mathrm{~min} 0.25 \mathrm{~mL}$ of Folin Ciocâlteu reagent was added followed by another span of 10 min after which absorbance was read at $540 \mathrm{~nm}$ (Sedlak et al. 1968).

\section{Determination of catalase}

$50 \mu \mathrm{L}$ of tissue homogenate was mixed with $1.95 \mathrm{~mL}$ of PBS7.0 pH and $1 \mathrm{~mL}$ of $0.7 \mathrm{mM} \mathrm{H} 2 \mathrm{O} 2$ solution. The absorbance was read at $240 \mathrm{~nm}$. (Claiborne et al. 1985).

\section{Determination of dopamine level}

The level of dopamine in the whole brain was estimated via UV-Visible spectroscopy. First, the standard linear curve of dopamine was derived via serial dilution of standard dopamine ( 50 to $500 \mathrm{ng} / \mathrm{mL}$ ). The detect in range of dopamine was set to 240-280 $\mathrm{nm}$ and the linear curve was obtained for Conc. v/s Abs. The supernatant obtained from each test group was diluted 10 times and the absorbance was read at $278 \mathrm{~nm}$ to detect the dopamine. Using the $\mathrm{y}=\mathrm{mx}+\mathrm{c}$ obtained equation from the linear curve and the sample absorbance, the whole brain dopamine level was estimated and expressed in ng/g of tissue (Khale et al. 2018).

\section{Histopathology examination}

Animals were euthanized at the end of the study, and the brain was isolated and placed in $10 \%$ formalin. Haematoxylin and eosin were used to stained the cortex and hippocampus slides. An electroscopic microscope with a magnification of $10 \times$ and $40 \times$ was used to examine the lesions.

\section{Statistical analysis}

The results were presented as Mean, Standard Error of the Mean (SEM) and SD. One-way and two-way ANOVA were used to determine the difference between the groups, followed by Bonferroni and Tukey's comparison tests, utilizing GraphPad Prism 6.0. The difference between the groups was considered significant and probability level at the degree of freedom at $0.05 *, * *, * * *, * * * *$ indicates $\mathrm{p}<0.05$, 0.01, 0.001, 0.0001 compared. Treatment group with Control group respectively \& \#, \#\#, \#\#,\#\#\#\# indicates $\mathrm{p}<0.05$, $0.01,0.001,0.0001$ compared to Negative control with Treatment group respectively.

\section{Results}

\section{Plant extraction and phytochemical screening}

The extract obtained from the aerial and root part is $64 \mathrm{~g}$ and $73 \mathrm{~g}$ respectively. The percentage yield (w/w) of Canna indica L. aerial part methanolic and root hydroalcoholic extract was found to be 6.4 and $7.4 \%$ respectively. The preliminary phytochemical screening of the aerial and root parts of Canna indica revealed the presence of carbohydrates, proteins, amino acids, alkaloids, flavonoids, terpenoids, steroids, polyphenols, tannins and cardiac glycosides.

\section{Total flavonoid and phenolic content}

The total flavonoid content of the methanolic extract of aerial part and hydroalcoholic extract of the root part of Canna indica was found to be 58.58 rutin equivalent/g of dry extract weight and $55.25 \mathrm{mg}$ rutin equivalent/g of dry extract weight, rutin respectively. Similarly, the total 
phenolic content of the hydroalcoholic extract of aerial part and hydroalcoholic extract of the root part of Canna indica was found to be $15 \mathrm{mg}$ gallic acidequivalent/g of dry extract weight and $8.83 \mathrm{mg}$ gallic acid equivalent/g of dry extract weight.

\section{In-vitro antioxidant assay}

\section{DPPH free radical scavenging assay}

The IC50 of Ascorbic acid was found to be $84.8153 \mu \mathrm{g} / \mathrm{mL}$ and the IC50 of Canna indica aerial part methanolic extract, root hydroalcoholic extract, and in combination was found to be $15.793,130.589,102.92 \mu \mathrm{g} / \mathrm{mL}$ respectively. The DPPH radical scavenging activity of Canna indica aerial part methanolic extract was found to be more potent compared to root alone and in a combination of aerial and root parts. The $\%$ inhibition and IC50 value are shown in Fig. 1a.

\section{NO free radical scavenging assay}

The IC50 of Ascorbic acid was found to be $133.20 \mu \mathrm{g} / \mathrm{mL}$ and the IC50 of Canna indica aerial part methanolic extract, root hydroalcoholic extract, and in combination was found to be $120.99,397.77,298.87 \mu \mathrm{g} / \mathrm{mL}$ respectively. The NO radical scavenging activity of Canna indica aerial part methanolic extract was found to be more potent compared to root alone and in a combination of aerial and root parts. The \% inhibition and IC50 value are shown in Fig. 1b

(a) DPPH free radical scavanging activity

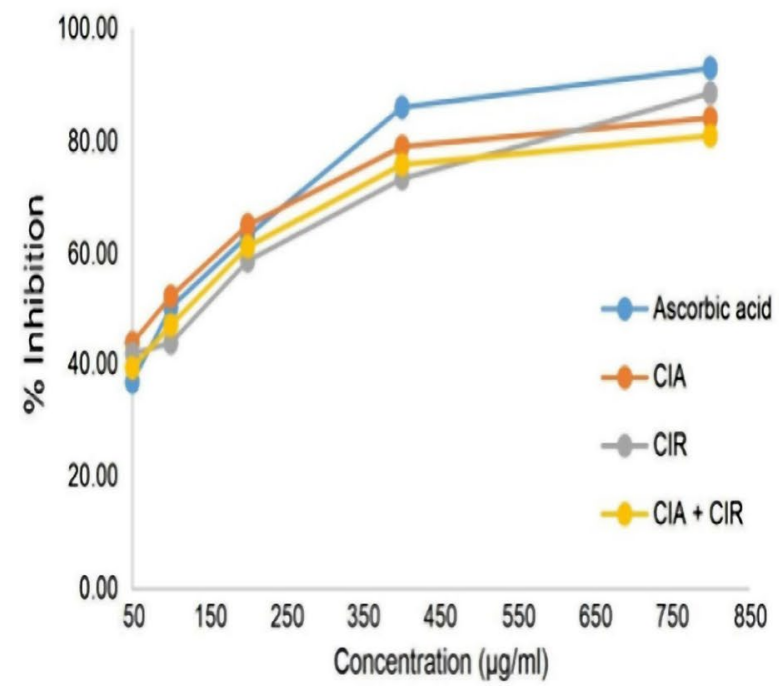

\section{In-vitro AChE inhibitory activity}

The IC50 of Donepezil was found to be $10.23 \mu \mathrm{g} / \mathrm{mL}$ and the IC50 of Canna indica aerial part methanolic extract and root hydroalcoholic extract was found to be $142.397 \mu \mathrm{g} / \mathrm{mL}$ and $214.666 \mu \mathrm{g} / \mathrm{mL}$ respectively. The AChE Inhibitory Activity of Canna indica aerial part methanolic extract was found to be more potent compared to root alone. The $\%$ inhibition and IC50 value are shown Fig. 2 and supplementary Table 1.

\section{In-vivo studies}

\section{Elevated Plus maze (EPM): Effect of Canna indica on Transfer latency (TL)}

The retrieval of memory "TL" from EPM was determined. A decline in the TL indicates the retrieval of memory. On the 0th day of the first treatment, the TL was found to be

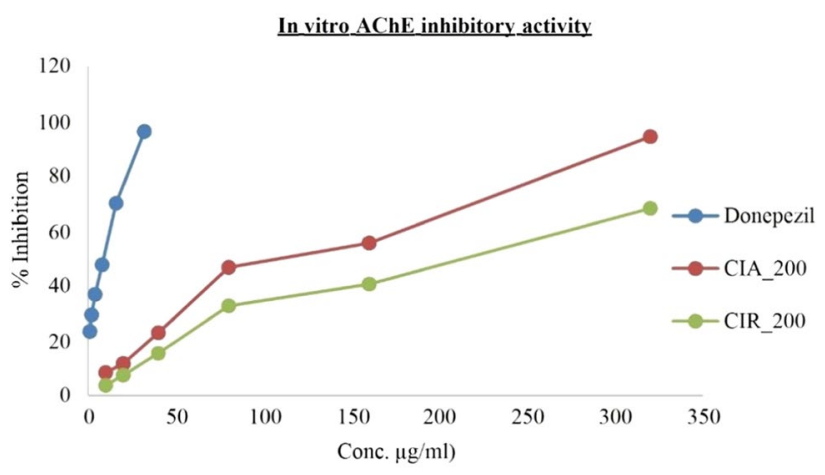

Fig. 2 Effect of Canna indica on AChE inhibition

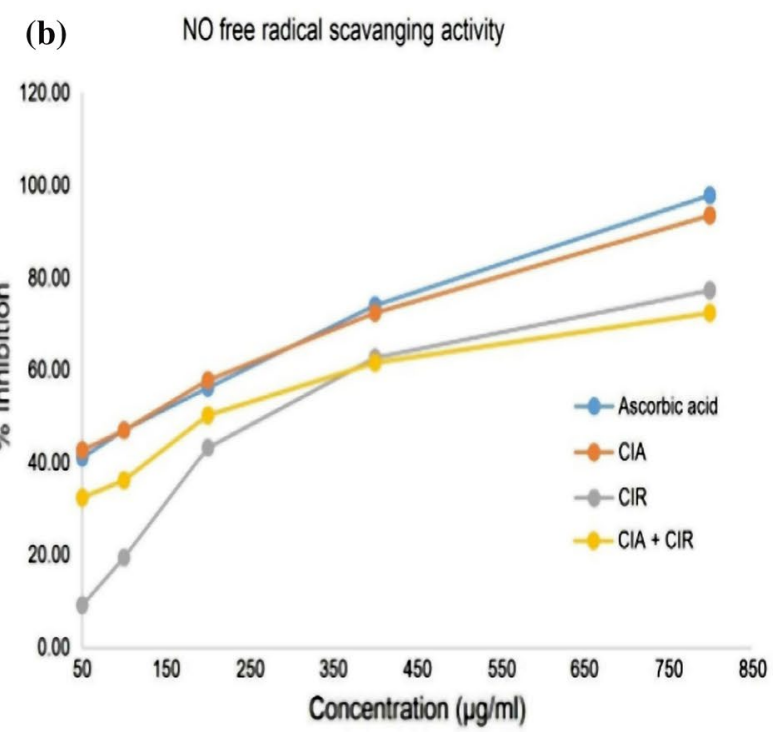

Fig. 1 Effect of Canna indica on a) DPPH free radical scavenging activity b) NO free radical scavenging activity 
similar to that of Acquisition trial readings. However, on the 7th day a significant increase in transfer latency (TL) was observed in the Negative control group (NC) compared to the control group $* * * \mathrm{p}<0.001$, whereas, treatment with Donepezil (PC) and CIA 200 showed a significant decline in the TL but no significant difference was observed in CIR 200 and CIA + CIR 200 group compared to NC group. Further, on the14th day and 21st day, a significant rise in TL was observed in the $\mathrm{NC}$ group compared to the control group $* * * \mathrm{p}<0.001$, whereas the treatment groups saw a decline in the TL as compared to NC group Among the three treatment groups, CIA 200 and CIA + CIR 200 groups were found be most effective as compared to $\mathrm{NC}$ and Donepezil group $\# \# \#$ p $<0.001$. The effect of CIA, CIR, and CIA + CIR on TL is shown in Fig. 3a and supplementary Table 2.

\section{Morris water maze: effect of Canna indica on escape latency time (ELT)}

Throughout the acquisition trial and on the $0^{\text {th }}$ day no significant difference was observed, among the groups. However, on the 7th day, the Negative control group (NC) exhibited a rise in the Escape latency time (ELT) $* * * \mathrm{p}<0.001$, whereas, treatment with CIA 200 and CIA + CIR 200 showed a decline in the ELT \#\# $\mathrm{p}<0.01$, however, no significant difference in ELT was observed in the Donepezil and CIR200 group compared to NC group\#\# $\mathrm{p}<0.01$. Further, on the 14th day and 21st days a remarkable rise in ELT was observed in the NC group $* * * * \mathrm{p}<0.0001$ compared to the control group, whereas, all the treatment groups exhibited a decline in ELT as compared to NC group \#\#\# $\mathrm{p}<0.0001$. The effect of CIA, CIR, and CIA + CIR on ELT is shown in Fig. $3 \mathrm{~b}$ and supplementary table 3 .

\section{Actophotometer: effect of Canna indica on locomotion activity}

Percentage change in locomotion was assessed by the actophotometer. On the 0th day and 7th day, no significant change in locomotion was observed among all the groups. However, on 14th and 21st day, a significant change in locomotion was observed in the NC group compared to the control group $(-1.57 \pm 0.309) * * * * \mathrm{p}<0.0001$. The treatment of Donepezil, CIA200 $(0.762 \pm 0.767) \# \# \#$ p $<0.0001$ CIR 200, and CIA + CIR $200(0.721 \pm 0.583) \# \# \#$ p $<0.0001$ reversed the decreased locomotion caused by $\mathrm{AlCl}_{3}$. The percentage change in locomotion is illustrated in Fig. $3 \mathrm{c}$ and supplementary Table 4.

\section{CPC: effect of Canna indica on escape latency time (ELT)}

During acquisition and 0th day, no significant difference in Escape latency time (ELT) was observed between the groups NC $(16.33 \pm 1.75)^{* * *} \mathrm{p}<0.001$ compared to CIR200 $(15.67 \pm 1.63)$. However, on the 7 th, 14th and
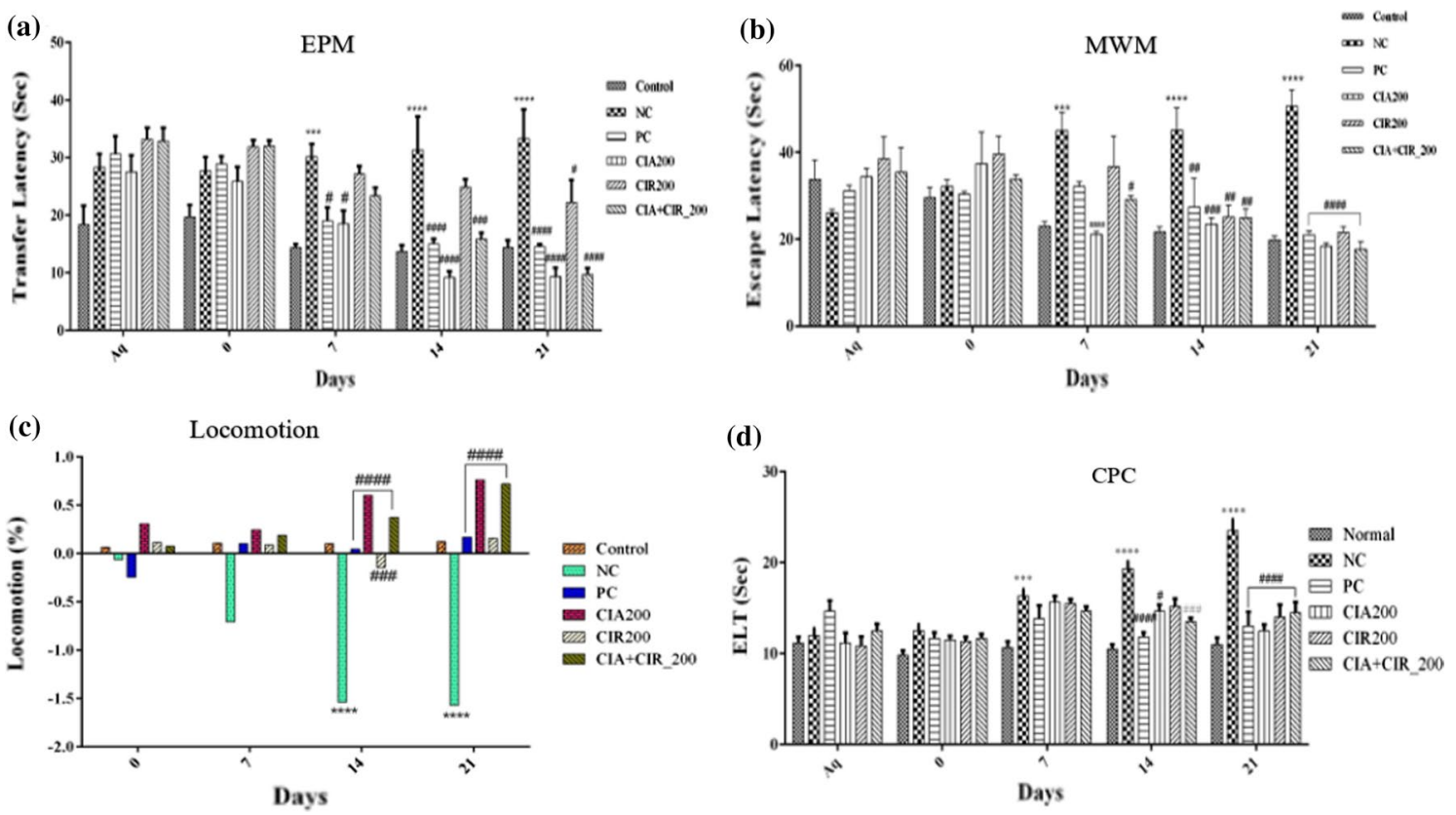

Fig. 3 Effect of Canna indica on a TL using EPM, b ELT using MWM, c) \% change in locomotion using Actophotometer, d ELT using CPC. $* \mathrm{p}<0.05, * * \mathrm{p}<0.01, * * * \mathrm{p}<0.001$, and $* * * * \mathrm{p}<0.0001$ is

compared to Control group; \#p $<0.05$, \#\#p $<0.01 \# \# \# p<0.001$, and $* * * * \mathrm{p}<0.0001$ is compared to $\mathrm{AlCl}_{3}$ induced $\mathrm{AD}$ group 


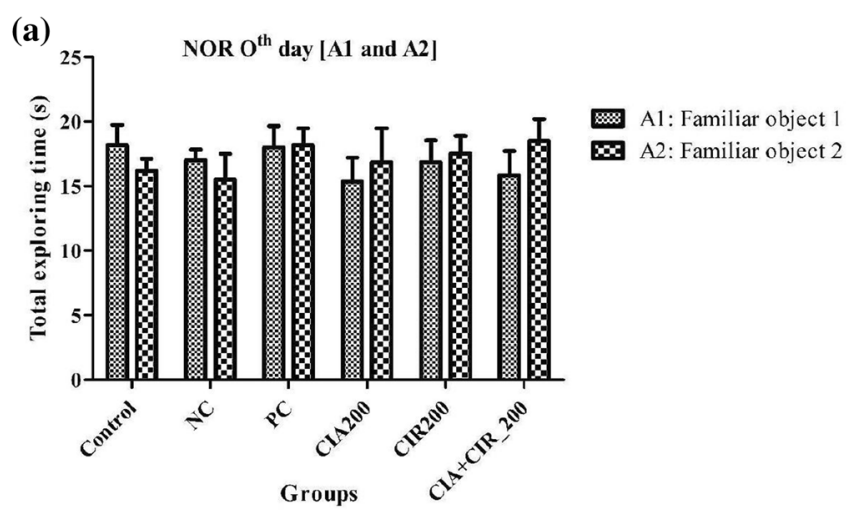

(b)

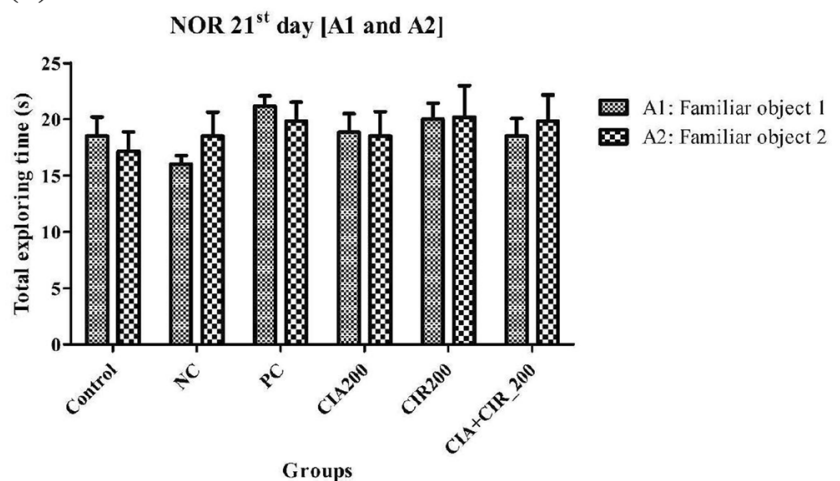

(c)
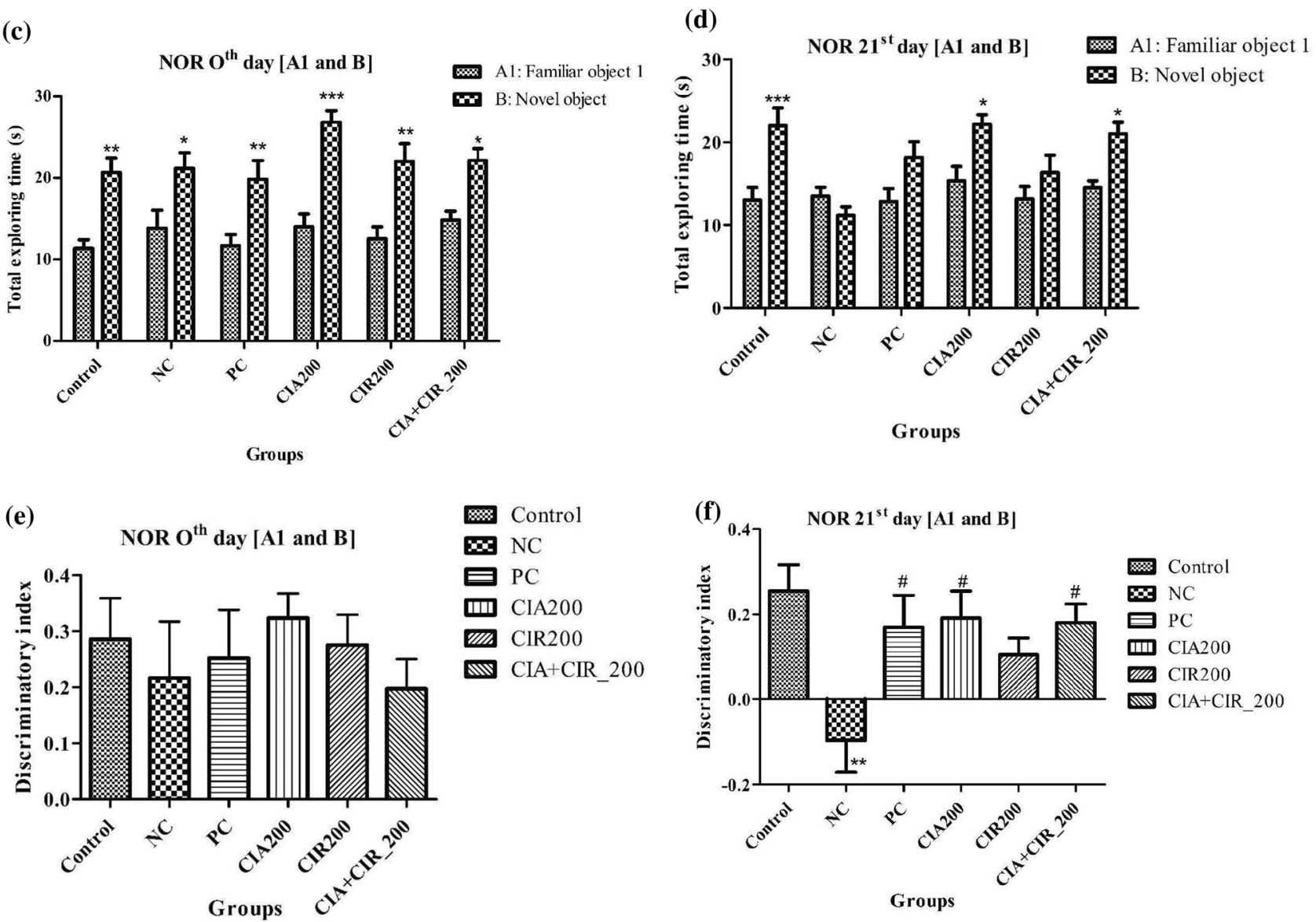

Fig. 4 Effect of Canna indica on novel object recognition a A1-A2 on 0th day b A1-A2 on 21st day, $\mathbf{c}$ A1-B on 0th day, d A1-B on 21st day, $\mathbf{e}$ DI of A1-B on 0th day, and $\mathbf{f}$ DI of A1-B on 21st day. ${ }^{*} \mathrm{p}<0.05$,

21 st days a significant increase in the ELT was seen in the NC group $(23.5 \pm 3.020) * * * * \mathrm{p}<0.0001$ as compared to the control group $(11 \pm 1.79)$, while treatment with Donepezil, CIA200 (12.5 \pm 1.64$) \# \# \#$ p $<0.0001$ and CIA + CIR 200 decreased the ELT $(14.5 \pm 2.88)$ \#\#\#\# $\mathrm{p}<0.0001$, When compared to the NC group $(23.5 \pm 3.02)^{* * * *} \mathrm{p}<0.0001$. The effect of Canna indica

$* * \mathrm{p}<0.01, * * * \mathrm{p}<0.001$, and $* * * * \mathrm{p}<0.0001$ is compared to Control group; $\# \mathrm{p}<0.05, \# \# \mathrm{p}<0.01 \# \# \# \mathrm{p}<0.001$, and $* * * * \mathrm{p}<0.0001$ is compared to $\mathrm{AlCl}_{3}$ induced $\mathrm{AD}$ group

on ELT in CPC is illustrated in Fig. 3c and supplementary Table 5 .

\section{NOR: effect of Canna indica on discriminatory index}

The effect of Canna indica on memory was evaluated via NOR by discrimination index for both A1-A2 and A1-B1 
(Supplementary table 6 and Fig. 4). On the 0th and 21st day, no significant difference was observed among all the groups for time spent with A1-A2 i.e., there was no significant difference in the time spent by the rats with the two familiar objects. However, on the 0th day, All the groups showed remarkable increase in time spent with B object compared to A object i.e., the time spent by the rats with the novel object (red box) was considerably higher than the time spent with the familiar object (green ball) suggestive of good retention of memory and natural exploratory behavior of the rats towards the novel object.

Similarly, on the 21 st day, a significant increase in novel object recognition (time spent with object B) was observed in control, CIA 200 and CIA + CIR compared to A1 object (\#\#p<0.01). Whereas, NC, PC, CIR 200 groups animals didn't show a significant increase in novel object recognition behavior. As for the discriminatory index, there was no significant difference in the DI among all the groups on the 0th day. On the other hand, a remarkable decline in DI was seen in the NC compared to the Control whereas PC, CIA 200, and CIA + CIR 200 group saw a remarkable rise in the DI.

\section{T-maze}

The effect of Canna.indica on \% Alternation was screened via T-maze. During 0th and 12th day, no significant difference in $\%$. Alternation is observed between the groups. However, on 21st day, a remarkable decline in \% Alternation in the $\mathrm{NC}$ group was seen compared to the control group while \% Alternation in the CIA 200 and CIA + CIR 200 group was remarkably raised when compared to the $\mathrm{NC}$ group (\#\#p <0.01). The effect of Canna. indica on \% Alternation in T-maze is illustrated in Fig. 5 and Table 7.

\section{In-vivo biochemical estimations}

Acetylcholinesterase level [Hippocampus and Cerebral Cortex]:

(A) Canna indica effect on AChE level.
The treatment of $\mathrm{AlCl}_{3}$ in the NC group remarkably increased the level of AChE in the cortex and hippocampus compared to the control group $(4.66 \pm 0.65)$. However, treatment with Donepezil, CIA200, CIR200, and CIA + CIR 200 significantly decreased the level of AChE in the cortex $(\# \# \# p<0.001)$ and hippocampus $\left(\mathrm{p}<0.001^{* * *}\right)$ compared to the NC group. All three treatment groups of Canna indica exhibited a potent inhibitory effect on AChE. The effect of Canna indica on AChE enzyme level in the cerebral cortex and hippocampus is shown in supplementary table 8 and Fig. 6a, b respectively.

\section{(B) Canna indica effect on BChElevel.}

The treatment of $\mathrm{AlCl}_{3}$ significantly increased the level of $\mathrm{BChE}$ in the cortex and hippocampus in the $\mathrm{NC}$ group as compared to the control group. However, treatment with Donepezil didn't show a significant effect on BChE level in both cortex and hippocampus compared to the NC group while treatment with CIA 200, CIR 200, and CIA + CIR $200(0.284 \pm 0.153)$ \#\#\#\# p <0.0001 significantly decreased the level of $\mathrm{BChE}$ in the cortex when compared to the NC group $(1.07 \pm 0.11)^{* * * *} \mathrm{p}<0.0001$, On the other hand, only CIA 200 and CIA + CIR $200(0.326 \pm 0.095)$ \#\#\#\# p $<0.0001$ significantly decreased the level of $\mathrm{BChE}$ in the hippocampus and CIR200 didn't show any effect as compared to the NC group $(0.936 \pm 0.079 * * * * \mathrm{p}<0.0001$. Among three treatment groups of Canna indica, CIA 200 and CIA + CIR 200 exhibited a potent inhibitory effect on BChE. The effect of Canna indica on BChE enzyme level in the cerebral cortex and hippocampus is shown in supplementary table 9 and Fig. 6c, d respectively.

\section{Canna indica effect on reduced GSH}

Treatment with $\mathrm{AlCl}_{3}$ in the $\mathrm{NC}$ group remarkably reduced GSH level in the whole brain compared to the control group. However, treatment with Donepezil, CIA 200, and CIA + CIR $200(\# \# \#$ p < 0.001) significantly increased the
Fig. 5 Effect of Canna indica on percentage alternation using T-Maze. *p $<0.05$, $* * \mathrm{p}<0.01, * * * \mathrm{p}<0.001$, and $* * * * \mathrm{p}<0.0001$ is compared to Normal group; \# $<0.05$, $\# \#$ p $<0.01 \# \#$ \# $<0.001$, and $* * * * \mathrm{p}<0.0001$ is compared to $\mathrm{AlCl}_{3}$ induced $\mathrm{AD}$ group

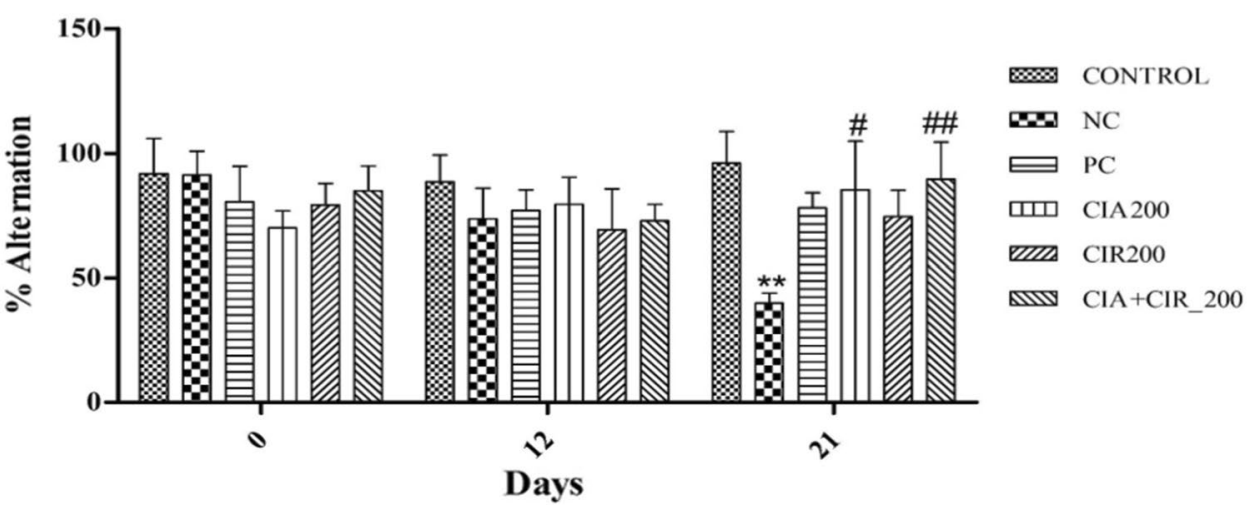



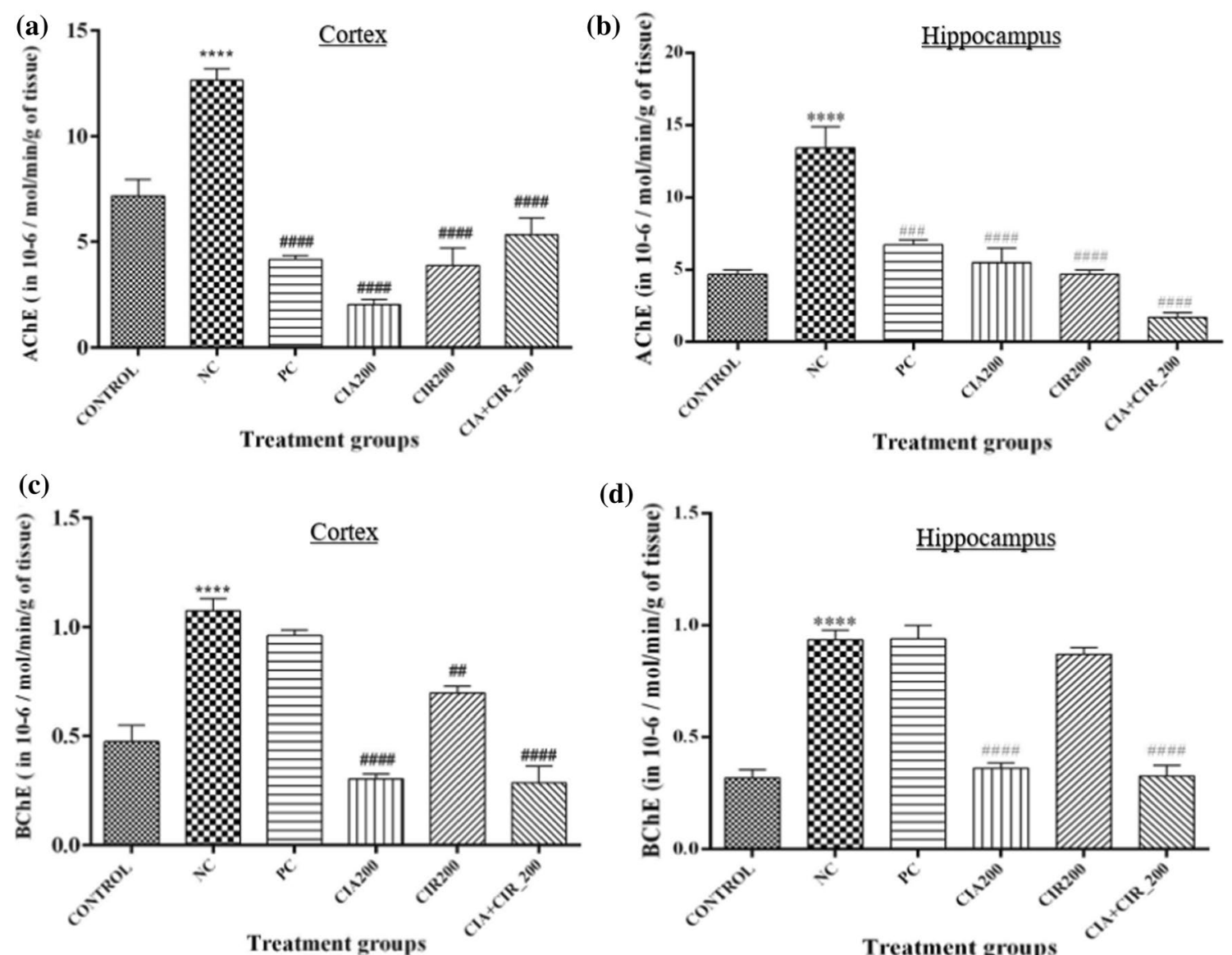

(d)

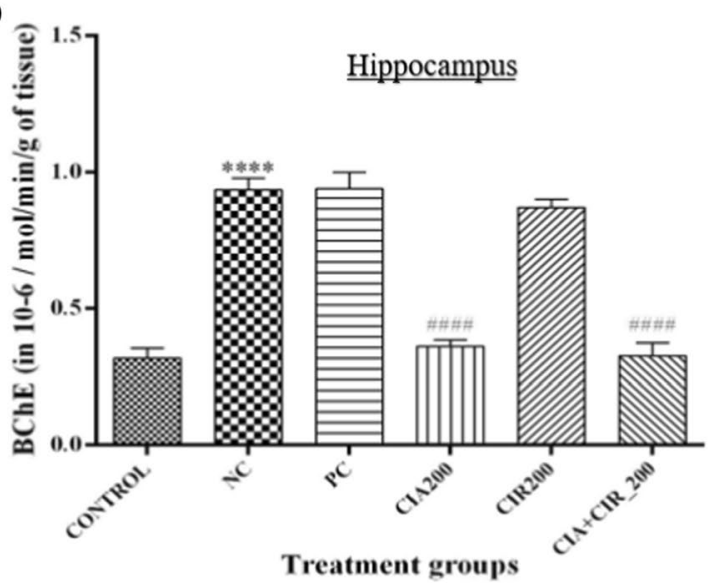

Fig. 6 Effect of Canna indica on brain AChE and BChE level. a $\mathrm{AChE}$ in cortex, b AChE in Hippocamous, $\mathbf{c} \mathrm{BChE}$ in cortex, and d BChE in Hippocampus. $* \mathrm{p}<0.05, * * \mathrm{p}<0.01, * * * \mathrm{p}<0.001$, and

$* * * * \mathrm{p}<0.0001$ is compared to Normal group; \#p $<0.05, \# \# \mathrm{p}<0.01$ $\# \# \#$ p $<0.001$, and $* * * * \mathrm{p}<0.0001$ is compared to $\mathrm{AlCl}_{3}$ induced $\mathrm{AD}$ group

level of GSH compared to the NC group (***p <0.001). Further, no significant change in GSH level is observed in the CIR200group compared to the NC group. The effect of Canna indica on whole brain GSH level is shown in supplementary Table 10 and Fig. 7a.

\section{Canna indica effect on malondialdehyde (MDA) level}

Treatment with $\mathrm{AlCl}_{3}$ in the $\mathrm{NC}$ group remarkably raised MDA level in the whole brain compared to the control group. However, treatment with Donepezil, CIA200, and CIA + CIR $200(\# \# \#$ p $<0.001)$ remarkably decreased the level of MDA compared to the NC group $(* * * p<0.001)$. Further, no significant change in MDA level is observed in the CIR200 group compared to the NC group. The effect of Canna indica on whole-brain MDA level is shown in supplementary table 10 and Fig. $7 \mathrm{~b}$.

\section{Canna indica effect on total protein (TP)}

The treatment with $\mathrm{AlCl}_{3}$ in the NC group didn't show a significant change in TP level but showed a slight increase in TP level in the whole brain compared to normal. However, treatment with Donepezil showed, not significant but decrease in the TP level compared to the NC. Further, CIA + CIR 200 and CIR200 didn't show a change in TP level, however, CIA 200 showed not significant but a slight decrease in TP level compared to the NC group. The effect of Canna indica on whole brain TP level is shown in supplementary table 10 and Fig. $7 \mathrm{c}$ respectively.

\section{Canna indica effect on superoxide dismutase (SOD)}

The treatment with $\mathrm{AlCl}_{3}$ in the NC group decreased the SOD level in the whole cerebrum compared to normal but data was found statistically non-significant. Also, Donepezil, CIA 200, CIR 200, and CIA + CIR 200 treatment didn't show any significant change in SOD level compared to the 
(a)

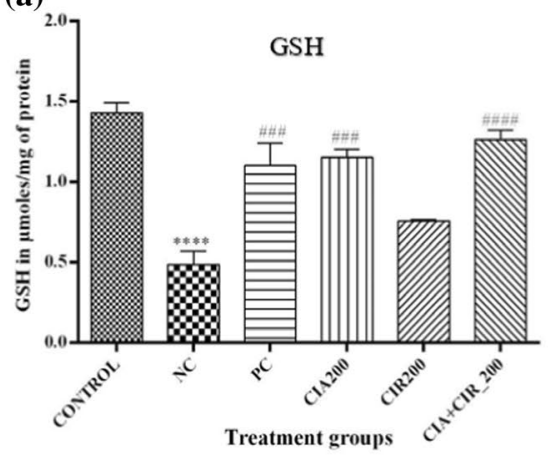

(d)

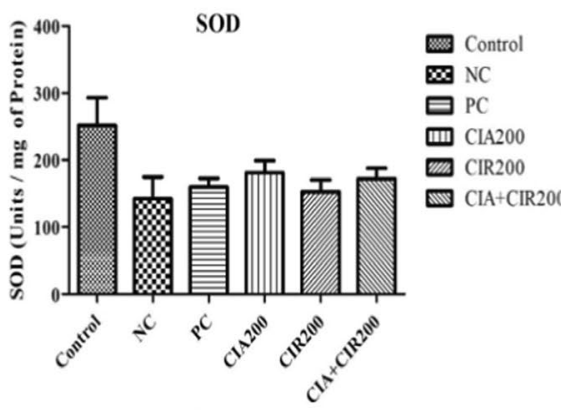

Treatment groups (b)

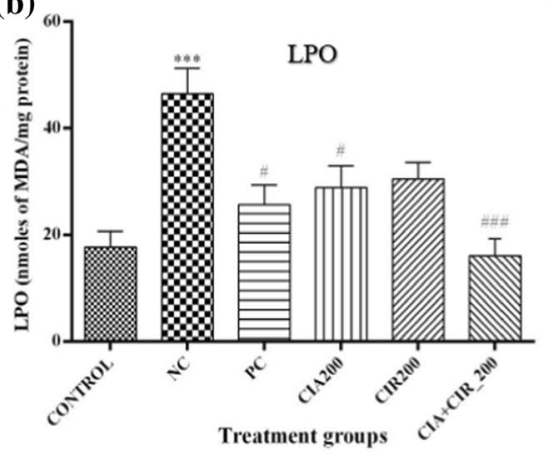

(e)

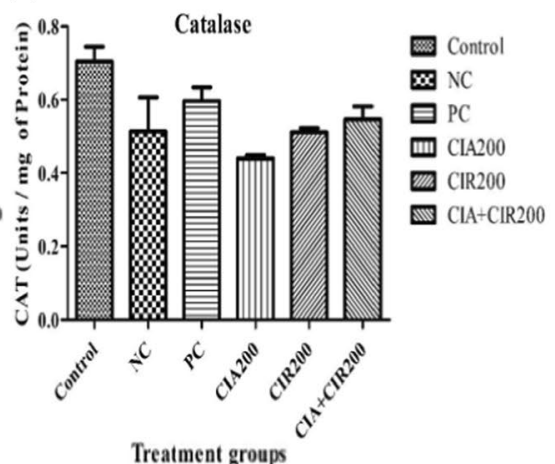

(c)

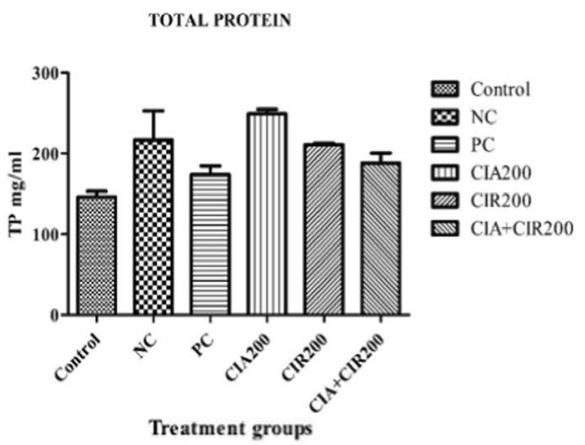

(f)

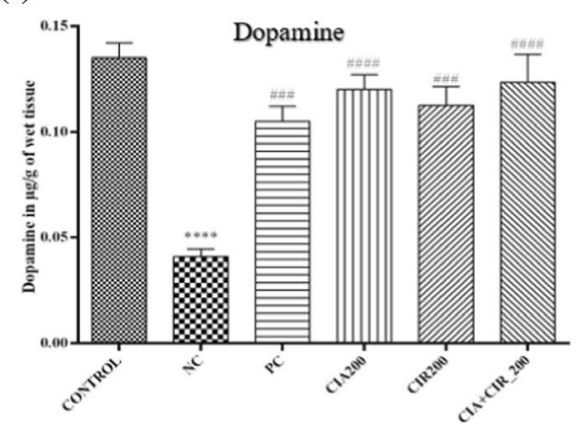

Treatment groups
Fig. 7 Effect of $C$. indica on whole brain antioxidant markers and dopamine level. a GSH, b LPO, c TP, d SOD, e CAT, and f Dopamine level. $* \mathrm{p}<0.05, * * \mathrm{p}<0.01, * * * \mathrm{p}<0.001$, and $* * * * \mathrm{p}<0.0001$ is

NC group. The effect of Canna indica on whole brain SOD level is shown in supplementary Table 10 and Fig. 7 d.

\section{Canna indica effect on catalase CAT}

Treatment with $\mathrm{AlCl}_{3}$ in the $\mathrm{NC}$ group didn't show a significant change in CAT level but showed a decrease in CAT level in the whole cerebrum. Also, Donepezil treatment showed slight increase in the CAT level but didn't show any significant change compared to the negative control. Further, CIA 200 and CIR 200 didn't show CAT activity, however, combination therapy CIA + CIR 200 showed not significant but a slight increase in CAT level compared to the NC group. The effect of Canna indica on whole brain CAT level is shown in supplementary Table 10 and Fig. 7e.

\section{Canna indica effect on dopamine level}

Treatment with $\mathrm{AlCl}_{3}$ in the $\mathrm{NC}$ group remarkably decreased Dopamine level in the whole cerebrum compared to the control group. However, treatment with Donepezil, CIA 200, CIR 200 and CIA + CIR $200(0.123 \pm 0.026) \# \# \#$ $\mathrm{p}<0.0001$ remarkably increased the level of Dopamine as compared to the $\mathrm{NC}$ group $\left(0.04 \pm 0.007^{* * * *}\right)$. The effect of compared to Normal group; \#p $<0.05$, \#\#p $<0.01 \# \#$ p $<0.001$, and $* * * * \mathrm{p}<0.0001$ is compared to $\mathrm{AlCl}_{3}$ induced $\mathrm{AD}$ group

Canna indica on whole brain Dopamine level is shown in supplementary Table 11 and Fig. 7f.

\section{Effect of Canna indica on whole-brain histopathology}

The histology of the control group cerebrum indicated mild cerebral oedema, cerebral congestion, neuronal eosinophilia, meningeal congestion, and no change was observed in RBC extravasation, macrophage influx, neuronal micro vacuolization, neuronal nuclear pyknosis, neutrophilic infiltration, neuronal karyorrhexis, reactive gliosis and vascular proliferation. However, the $\mathrm{NC}$ group histogram indicated severe damage in the above mentioned parameters $(+++$ to +$)$. The PC and CIA and CIA+CIR groups reversed the $\mathrm{AlCl}_{3}$ induced damage. The histopathology of the brain (cortex and hippocampus) at $10 \times$ and $40 \times$ magnification is shown in Figs. 8 and Fig. 9 respectively and Table 12 (Table 1).

\section{Discussion}

The neuroprotective and memory enhancing mechanism of action of Canna indica has been shown in this study via in vitro and in vivo. Firstly, using the interceptive 

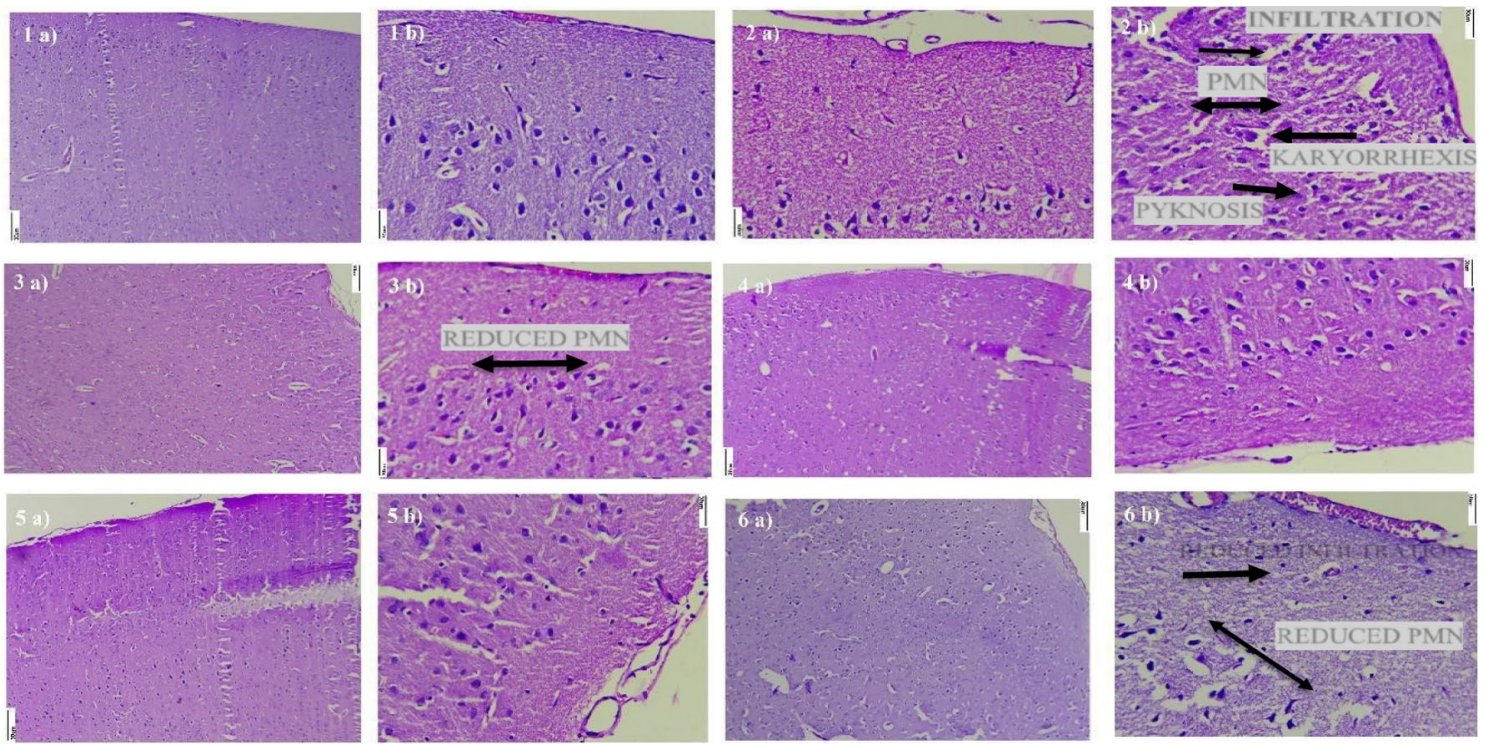

Fig. 8 Effect of $C$. indica on cortex. $\mathbf{a} \times 10 \mathbf{b} \times 40$. 1) Control 2) NC 3) PC 4) CIA200, 5) CIR200, 6) CIA + CIR 200
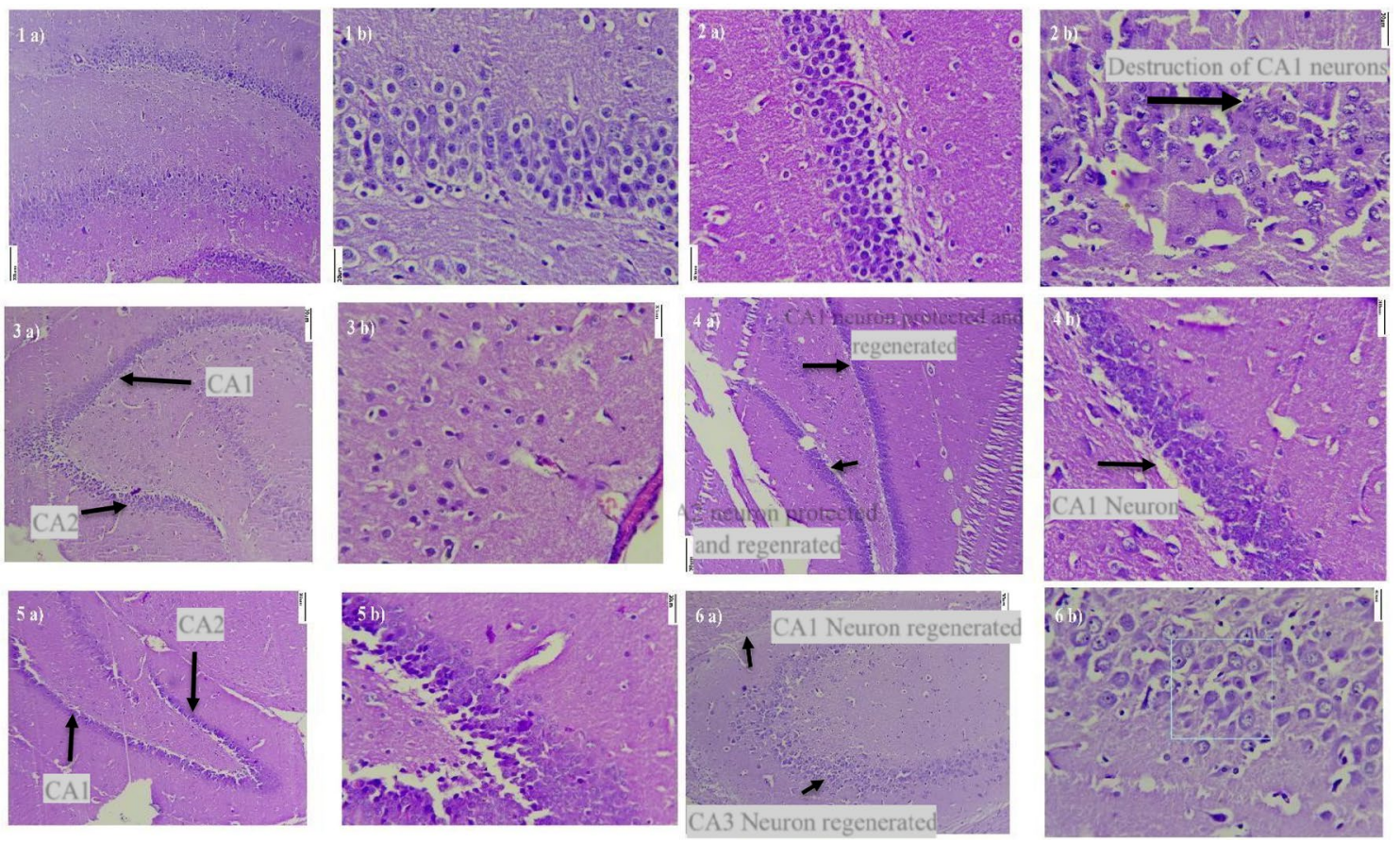

Fig. 9 Effect of $C$. indica on hippocampus. $\mathbf{a} \times 10 \mathbf{b} \times 40$. 1) Control 2) NC 3) PC 4) CIA200 5) CIR2006) CIA + CIR 200

and exterceptive models like MWM, EPM, Actophotometer, CPC, NOR, and T-Maze, analyzing the biochemical (AChE, BChE, GSH, MDA, TP, SOD, CAT, Dopamine) level from the cerebrum, the memory restoring function of Canna indica against $\mathrm{AlCl}_{3}$ mediated memory dysfunction in rats was investigated. The MWM was used to assess spatial memory. Administration of $\mathrm{AlCl}_{3}$ significantly raises the ELT and treatment with Donepezil and Canna indica
$[\mathrm{A}+\mathrm{R}]$ indicated a critical decline in ELT. EPM was used to determine the transfer latency (TL). The TL was significantly increased in the $\mathrm{AlCl}_{3}$ treated rats. However, prolonged Donepezil and Canna indica $[\mathrm{A}+\mathrm{R}]$ treatment for 21 days lead to a remarkable reduction in TL. The change in body movement was observed by measuring locomotor activity through actophotometer. Administration of $\mathrm{AlCl}_{3}$ significantly decreased locomotory activity in rats and 


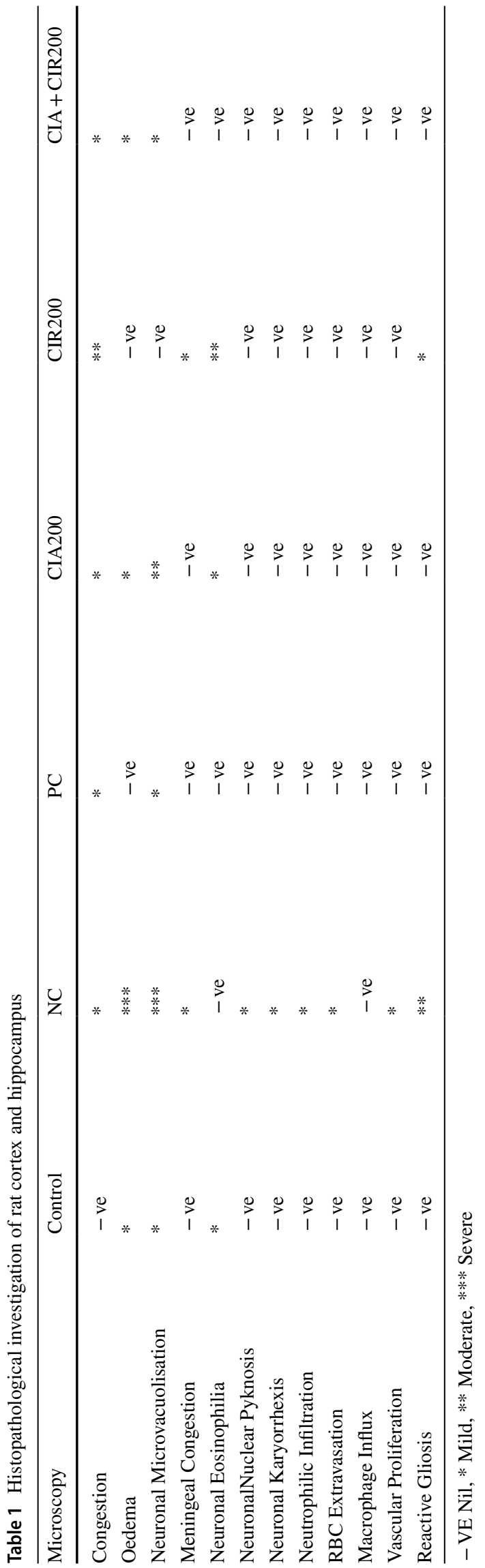

treatment with Donepezil and Canna indica reversed this mechanism. Further, CPC was used to investigate cognitive function, primarily a response to conditioned stimuli during learning and memory. $\mathrm{AD}$ induced using $\mathrm{AlCl}_{3}$ exhibited a noteworthy rise in ELT on day 21st and treatment with Canna indica $[\mathrm{A}+\mathrm{R}]$ and Donepezil successfully reversed this change. Further, to analyze the recognition memory and the ability to discriminate between two discrete objects, the NOR apparatus was used. Treatment with $\mathrm{AlCl}_{3}$ exhibited a significant decline in the discriminatory index on day 21st while treatment with Canna indica $[\mathrm{A}$ and $\mathrm{A}+\mathrm{R}]$ and Donepezil remarkably raised the discriminatory index. Finally, the exploratory behavior as well as the working memory of the rats was analyzed by using the T-maze apparatus. Treatment with $\mathrm{AlCl}_{3}$ exhibited a remarkable decline in \% alternation on day 21 st and treatment with Canna indica $[\mathrm{A}+\mathrm{R}]$ significantly raised the $\%$ alternation. These findings suggest that Canna indica memory improving function protects against $\mathrm{AlCl}_{3}$ Induced memory loss.

Cholinesterase's function, GSH, MDA, TP, SOD, CAT, and Dopamine level in the cerebrum were examined. The level of ACh and BCh chemicals associated with memory improvement, is diminished in AD because of fast hydrolysis by $\mathrm{AChE}$ and $\mathrm{BChE}$ action respectively. In the present study, the Invitro results suggest that CIA and CIR possess an AChE inhibitory potency. Similarly, chronic administration of CIA and CIR in rats exhibited a remarkable reduction in the AChE and BChE activity in both cortex and hippocampus, which suggests that Canna indica [A and R] both possess AChE and $\mathrm{BChE}$ inhibitory activity in a dose dependent manner. This may be due to the presence of various phytoconstituents in the plant such as flavonoids, terpenes, sesquiterpenes and sterols.

During physiological and pathological processes, free radicals and reactive oxygen species (ROS) are generated ROS are important in phagocytosis, enzyme activation, and cell cycle control, among other cell signaling pathways. (Manoharan et al. 2016) An imbalance in free radical and reactive oxygen species (ROS) formation weakest the antioxidant defense system, resulting in cell damage and inflammation. $\mathrm{O} 3, \mathrm{H} 2 \mathrm{O} 2$, and $\mathrm{NO} 2$ are the primary free radicals involved in oxidative stress and the development of AD.Further, more the generation (production) of ROS causes a variety of undesirable effects, including DNA harm, lipid peroxidation, and protein mutilation. It is wellknown that "plant extracts with higher flavonoid and phenolic content have the highest DPPH scavenging and nitric oxide scavenging activity" (Manoharan et al. 2016). In the present study, in vitro antioxidant assays showed that Canna indica to possess DPPH and NO radical scavenging activity. Further, administration of CIA and CIR showed remarkable change in the antioxidant level in the whole brain viz., GSH, MDA, TP, and CAT level. The antioxidant effect of 
Canna indica may be due to the abundant presence of flavonoids and triterpenoids in the plant. Further, Dopamine a neurotransmitter present in the VTA, is involved in reward motivated actions and aids in the regulation of expression and the formation of new memories. In the present study investigation, $\mathrm{AlCl}_{3}$ administration significantly decreased the level of Dopamine, and treatment with Donepezil and Canna indica reversed the above changes in dopamine level. Lastly, the histopathology examination of the brain of the normal animals revealed no significant changes, while the histopathology of the cerebrum in animals treated with $\mathrm{AlCl}_{3}$ revealed significant changes viz., cerebral oedema, cerebral congestion, neuronal eosinophilia, meningeal congestion etc. Also, it was found that CA1 neurons and CA3 neurons (subdivision of CA1 neurons) which are majorly implicated in the formation and retrieval of hippocampal dependent memories were significantly disrupted. (Bartsch et al. 2011) Treatment with Donepezil and Canna indica on the other hand, resulted in normal histopathology of the cerebrum, indicating that Donepezil and Canna indica reversed the harm caused by $\mathrm{AlCl}_{3}$.

\section{Conclusion}

In this study, In vivo and In vitro experiments were employed to decode the intramolecular interaction of Canna indica memory enhancement activity. Chronic Canna indica therapy improves memory damage caused by $\mathrm{AlCl}_{3}$ by restoring cholinergic system activity, regulating antioxidant pathways, and increasing dopamine levels. The study utilized MWM, EPM, CPC, Actophotometer, NOR, and T-Maze to demonstrate the memory functions modulated by both $\mathrm{AlCl}_{3}$ and Canna indica. It can be said that the study results are comparable with the clinically approved molecule Donepezil. However, the current study is only limited to preclinical and which further validation using other AD models and gene expression level studies are needed to be carryout to explore the Canna indica pharmacotherapy in Alzheimer disease.

Supplementary Information The online version contains supplementary material available at https://doi.org/10.1007/s13596-021-00627-x.

Acknowledgements The authors thanks to Prof. Dr. S.S. Jalapure Principal, and Dr. N.A. Khatib, HOD of department of Pharmacology and Toxicology, KLE college of Pharmacy, Belagavi for providing necessary facilities to conduct the work. Authors thanks to Cipla, Verna, Goa for providing Donepezil $\mathrm{HCl}$ as a gift sample.

Author's contribution Prakash R. Biradar helped Conceptualization the study design, critical review and analysis of the manuscript and supervised the experiments. Prachi Ojha designed the study, conducted the experiments, and drafted the manuscript. Siddarth Tubachi, Vishal Patil assisted in data analysis and manuscript.
Funding None.

\section{Declarations}

Ethical statement The study protocol was reviewed and approved by the Institutional Animal Ethics Committee, KLE College of Pharmacy, Belagavi, and Resolution No. KLECOP/CPCSEA- Reg.No.221/Po/ Re/S/2000/CPCSEA, Res. No 29-03/09/2020. The animal experiments were carried out in accordance with the CPCSEA guidelines.

Conflict of interest Prachi S. Ojha has no conflict of interest. Prakash R. Biradar has no conflict of interest. Siddarth Tubachi has no conflict of interest. Vishal S. Patil has no conflict of interest.

\section{References}

Alan MP (2002) (2002) Pharmacotherapy for Alzheimer's disease: progress and prospects. Trends Pharmacol Sci 23(9):426-433

Ali TB, Schleret TR, Reilly BM, Chen WY, Abagyan R (2015) Adverse effects of cholinesterase inhibitors in dementia, according to the pharmacovigilance data bases of the United-States and Canada. PLoS ONE 10(12):1-10

Alistair B, Jane BE, Konrad M (2002) Alzheimer's disease. Lancet 360:163-165

Ann EP, Vazdarjanova A (2003) McGaugh JL Muscarinic cholinergic influences in memory consolidation. Neurobio Learn Memory 80:178-193

Antunes M, Biala G (2012) The novel object recognition memory: neurobiology, test procedure, and its modifications. Cogn Process 13(2):93-110. https://doi.org/10.1007/s10339-011-0430-z

Baba SA, Malik SA (2014) Evaluation of antioxidant and antibacterial activity of methanolic extracts of Gentiana kurrooroyle. Saudi J Biol Sci 21:493-498. https://doi.org/10.1016/j.sjbs.2014.06.004

Bachurin SO, Bovina EV, Ustyugov AA (2017) Drugs in clinical trials for Alzheimer's disease: the major trends. Med Res Rev 5:1186-1225

Bartsch T, Dohring J, Rohr A, Jansen O (2011) Deuschl G (2011) CA1 neurons in the human hippocampus are critical for autobiographical memory, mental time travel, and autonoetic consciousness. Proc Natl Acad Sci 108(42):17562-17567

Bhuvanendran S, Kumari Y, Othman I (2018) Amelioration of cognitive deficit by Embelin in a Scopolamine-induced Alzheimer's disease-like condition in a rat model. Front Pharmacol 9(6):1-12

Biradar P, Patil V, Joshi H, Khanal P, Mallapur S (2020) Experimental validation and network pharmacology evaluation to decipher the mechanism of action of Erythrina variegata L. bark against scopolamine-induced memory impairment in rats. Adv Tradit Med 26:1-4

Blennow K, De LMJ, Zetterberg H (2006) Alzheimer's Dis 368:387-403

Boora F, Chirisa E, Mukanganyama S (2014) Evaluation of nitrite radical scavenging properties of selected Zimbabwean plant extracts and their phytoconstituents. J Food Process 2014:1-7

Cacabelos R, Alvarez A, Lombardi V (2000) Pharmacological treatment of Alzheimer disease: from psychotropic drugs and cholinesterase inhibitors to pharmacogenomics. Drug Today (barc) 36(7):415-499

Chandra V, Ganguli M, Pandav R, Johnston J, Belle S, Dekosky ST (1998) Prevalence of Alzheimer's disease and other demands in rural India. Neurology 51:1000-1008 
Chigurupati S, Alharbi NA, Sharma AK, Alhowail A, Vardharajula VR, Vijayabalan S, Das S, Kauser F, Amin E (2021) Pharmacological and pharmacognostical valuation of Canna indica leaves extract by quantifying safety profile and neuroprotective potential. Saudi Journal of Biological Sciences. 2021 Jun 1

Claiborne A (1985) Catalase activity. In: Greenwald RA (ed) CRC hand book of methods for oxygen radical research. CRC Press, Boca Raton, Florida, USA, pp 283-284

Colović MB, Krstić DZ, Lazarević-Pašti TD, Bondžić AM, Vasić VM (2013) Acetylcholinesterase inhibitors: pharmacology and toxicology. Currneuropharmacol 11(3):315-335

Cummings J, Lee G, Mortsdorf T, Ritter A, Zhong K (2017) Alzheimer's disease drug development pipeline: 2017. Alzheimer's Dement Transl Res Clin Interv 3(3):367-384

Deutsch JA (1971) The cholinergic synapse and the site of memory. Science 174:788-794

Dhanasekaran S, Perumal P, Palayan M (2015) In-vitro Screening for acetylcholinesterase enzyme inhibition potential and antioxidant activity of extracts of Ipomoea aquatica Forsk: therapeutic lead for Alzheimer's disease. J Appl Pharm Sci 5:12-126

Du X, Wang X, Geng M (2018) Alzheimer's disease hypothesis and related therapies. Translational Neurodegeneration 7(2):1-7

Ellman GL (1959) Tissue sulfhydryl groups. Arch Biochem Biophys 82(1):70-77

Ellman GL, Courtney KD, Andres V, Featherstone RM (1961) A new and rapid colorimetric determination of acetylcholinesterase activity. BiochemPharmaco 7(2):88-95

Ezio G (2000) Cholinesterase inhibitors stabilize Alzheimer's disease. Neurochem Res 25(9/10):1185-1190

Ferreira-Vieira TH, Guimaraes IM, Silva FR, Ribeiro FM (2016) Alzheimer's disease: Targeting the Cholinergic System. CurrNeuropharmacol 14(1):101-115

Gautam S, Gautam A, Chhetri S, Bhattarai U (2020) Immunity Against COVID-19: Potential Role of AyushKwath. J Ayurveda Integr Med

Gianni B, Antonio M (1998) Is there a rational effort the use of acetylcholinesterase inhibitors in the therapy of Alzheimer's disease. Euro J Pharmacol 346:1-13

Goverdhan P, Sravanthi A, Mamatha T (2012) Neuroprotective effects of meloxicam and selegiline in scopolamine-induced cognitive impairment and oxidative stress. Int J Alzheimer's Dis

Hippius H, Neundörfer G (2003) The discovery of Alzheimer's disease. Dialogues Clin Neurosci 5(1):101-108

Ishola IO, Ikuomola BO, Adeyemi OO (2018) Protective role of Spondiasmombin leaf and Cola acuminata seed extracts against scopolamine- induced cognitive dysfunction. Alexandria J Med 54(1):27-39

Kanase V, Vishwakarma S (2018) Treatment of various diseases by Canna indica L. promising herb. Asian J Pharm Clin Res 11(12):51-56

Kasture S (2003) Pharmacotherapy of Alzheimer's disease. Proceedings of the AICTE sponsored national seminar; 2003 Aug 22-23; Guru Jambheshwar University (Haryana) 31-41

Khale AS, Kolhe SU, Tembhurne SV (2018) Neuropharmacological evaluation of Sesbania sesban using experimental animals. World J Pharm Res 7(12):698-717

Korczyn AD, Vakhapova V (2007) The prevention of the dementia epidemic. J Neurol Sci 257:2-4

Kosasa T, Kuriya Y, Matsui K, Yamanishi Y (2000) Inhibitory effect of orally administered donepezil hydrochloride (E2020), an over treatment for Alzheimer's disease, on cholinesterase activity in rats 389:173-179

Lin FR, Ferrucci L, Metter EJ, An Y, Zonderman AB, Resnick SM (2011) Hearing loss and cognition in the Baltimore longitudinal study of aging. Neuropsychology 25(6):763
Mahdi O, Baharuldin MT, Nor NH, Chiroma SM, Jagadeesan S, Moklas MA (2019) Chemicals used for the induction of Alzheimer's disease-like cognitive dysfunctions in rodents. Biomed Res Ther 6(11):3460-3484

Manoharan S, Guillemin GJ, Abiramasundari RS, Essa MM, Akbar M, Akbar MD (2016) The role of reactive oxygen species in the pathogenesis of Alzheimer's disease, Parkinson's disease, and Huntington's Disease: a mini review. Oxid Med Cell Longev 2016:1-15

Margaret ME (2001) Is an effective immune intervention for Alzheimer's disease in prospect? Trends Pharmacol Sci 22(1):2-3

Mayo clinic Alzheimer's: drugs help manage symptoms. https://www. mayoclinic.org/diseasesconditions/alzheimersdisease/indepth/ alzheimers/art-20048103. Assessed on 05 Dec 2021

Misra HP, Fridovich I (1972) The role of superoxide anion in the autooxidation of epinephrine and a sample assay for superoxide dismutase. J Biol Chem 247:3170-3175

Nigel HG, Tada U (2001) Qian-Sheng Y A new therapeutic target in Alzheimer's disease treatment: attention to butyrylcholinesterase. Curr Med Res Opin 17(3):159-165

Noreen H, Semmar N, Farman M, Mccullagh JSO (2017) Measurement of total phenolic content and antioxidant activity of aerial parts of medicinal plant Coronopusdidymus. Asian Pac J Trop Med

Ogura H, Kosasa T, Araki S (2000) Yamanishi Y Pharmacologicalpropertiesofdonepezil hydrochloride (Aricept) a drug for Alzheimer's disease. Nihon YakurigakuZasshi 115(1):45-51

Ohkawa H, Ohishi N, Yagi K (1979) Assay for Lipid Peroxides in Animal Tissues by Thiobarbituric Acid Reaction 358:351-358

Oladotun PB, Akinsiku AA, Adeyemi AO et al (2019) Qualitative analysis, total phenolic content, FT-IR and GC-MS characterisation of Canna indica: bio reducing agent for nanoparticles synthesis. J Phys: Conf Ser 1299:012135

Palle S, Neerati P (2017) Quercetin nanoparticles attenuates scopolamine induced spatial memory deficits and pathological damages in rats. Bull Fac Pharmacy, Cairo Univ 55(1):101-106

Parihar MS, Hemnani T (2004) Alzheimer's disease pathogenesis and therapeutic interventions. J Clin Neurosci 11(5):456-467

Paul EG (2003) Acetylcholine modulation of neural systems involved in learning and memory. Neurobiol Learn Memory 80:194-210

Prema A, Justin Thenmozhi A, Manivasagam T, Mohamed Essa M, Guillemin GJ (2017) Fenugreek seed powder attenuated aluminum chloride-induced tau pathology, oxidative stress, and inflammation in a rat model of Alzheimer's disease. J Alzheimers Dis 60(s1):S209-S220

Ramakrishnan P, Chandrasekhar T, Muralidharan P. (2015) Cognitive enhancing, antiacetylcholinesterase, and antioxidant properties of Tagetespatulaons copolamine induced amnesia in mice. Int $\mathrm{J}$ Green Pharm 167-174.

Raymond T, Bartus, Reginald L (1982) The cholinergic hypothesis of geriatric memory dysfunction. Science 217:408-417

Sarje SK, Ingole K, Angad S, Priya B, Ghiware NB (2019) A pharmacognostic and pharmacological review on Canna indica Linn. Int J Res Pharm Chem 9(3):61-77

Scott A, Small MD (2001) Age-related memory decline. Arch Neurol 58:360-364

Sedlak J, Lindsay RH (1968) Estimation of total, protein-bound, and non-protein sulfhydryl groups in tissue with Ellman's reagent. Anal Biochem 25:192-205

Shigeta M, Homma A (2001) Donepezil for Alzheimer's disease: pharmacodynamic, pharmacokinetic, and clinical profiles. CNS Drug Rev 7(4):353-368

Sugimoto H (2008) The new approach in development of anti-Alzheimer's disease drugs via the cholinergic hypothesis. Chemico Biol Interactions 175:204-208

Sweatt JD (2009) Aging related memory disorders-Alzheimer's Disease. Elsevier Inc. 2009:292-319 
Talluri MR, Killari KN, Viswanadha Murthy Manepalli N, Kanduri P, Kiran kumar B (2018) Protective effect of Canna indica on cerebral ischemia-reperfusion injury in rats, Agric Nat Resour

Terry Jr. AV, Buccafusco JJ (2003) The cholinergic hypothesis of age an Alzheimer's disease related cognitived eficits: recent challenges and the implications for novel drug development. J Pharmacol Exp Ther 306(3):821-827

Tharun G, Kumar P (2013) Evaluation of antioxidant potential and antimicrobial activity of successive extracts of Pimpinella tirupatiensis. JOPR J Pharm Res 7(9):817-822

Wenk GL (1998) Assessment of spatial memory using the T maze. Curr Protoc Neurosci 4(1):8-5
Wikipedia. Canna indica.https://en.wikipedia.org/wiki/Canna_indica. Accessed on 24 Apr 2021

Zhishen J, Mengcheng T, Jianming W (1999) (1999) The determination of flavonoid content in mulberry and their scavenging effects on superoxide radicals. Food Chem 64:555-559

Publisher's Note Springer Nature remains neutral with regard to jurisdictional claims in published maps and institutional affiliations. 